\title{
Modulation of Prostanoids Profile and Counter-Regulation of SDF-1 $\alpha /$ CXCR4 and VIP/VPAC2 Expression by Sitagliptin in Non-Diabetic Rat Model of Hepatic Ischemia-Reperfusion Injury
}

\author{
Małgorzata Krzystek-Korpacka ${ }^{1, *}$, Mariusz G. Fleszar ${ }^{1}{ }^{(D}$, Paulina Fortuna $^{1}$, Kinga Gostomska-Pampuch ${ }^{1}(\mathbb{D}$, \\ Łukasz Lewandowski ${ }^{1}$ (D), Tomasz Piasecki ${ }^{2}$, Bogna Kosyk ${ }^{3}$, Adam Szeląg ${ }^{4}$ and Małgorzata Trocha ${ }^{4, *}$ (D)
}

1 Department of Biochemistry and Immunochemistry, Wroclaw Medical University, 50-368 Wrocław, Poland; mariusz.fleszar@umw.edu.pl (M.G.F.); paulina.fortuna@umw.edu.pl (P.F.); kinga.gostomska-pampuch@umw.edu.pl (K.G.-P.); lukasz.lewandowski@umw.edu.pl (Ł.L.)

2 Department of Epizootiology and Clinic of Bird and Exotic Animals, Wroclaw University of Environmental and Life Sciences, 50-366 Wrocław, Poland; tomasz.piasecki@upwr.edu.pl

3 Institute of Soil Science and Environmental Protection, Wroclaw University of Environmental and Life Sciences, 50-375 Wroclaw, Poland; bogna.kosyk@upwr.edu.pl

4 Department of Pharmacology, Wroclaw Medical University, 50-345 Wrocław, Poland; adam.szelag@umw.edu.pl

Citation: Krzystek-Korpacka, M.;

Fleszar, M.G.; Fortuna, P.;

Gostomska-Pampuch, K.;

Lewandowski, Ł.; Piasecki, T.; Kosyk, B.; Szelag, A.; Trocha, M. Modulation of Prostanoids Profile and Counter-Regulation of SDF- $1 \alpha / C X C R 4$ and VIP/VPAC2 Expression by Sitagliptin in Non-Diabetic Rat Model of Hepatic Ischemia-Reperfusion Injury. Int. J . Mol. Sci. 2021, 22, 13155. https:// doi.org/10.3390/ijms222313155

Academic Editor: Giuliano Ramadori

Received: 1 November 2021

Accepted: 4 December 2021

Published: 5 December 2021

Publisher's Note: MDPI stays neutral with regard to jurisdictional claims in published maps and institutional affiliations.

Copyright: () 2021 by the authors. Licensee MDPI, Basel, Switzerland. This article is an open access article distributed under the terms and conditions of the Creative Commons Attribution (CC BY) license (https:// creativecommons.org/licenses/by/ $4.0 /)$.
* Correspondence: malgorzata.krzystek-korpacka@umw.edu.pl (M.K.-K.); malgorzata.trocha@umw.edu.pl (M.T.)

\begin{abstract}
Molecular mechanisms underlying the beneficial effect of sitagliptin repurposed for hepatic ischemia-reperfusion injury (IRI) are poorly understood. We aimed to evaluate the impact of IRI and sitagliptin on the hepatic profile of eicosanoids (LC-MS/MS) and expression/concentration (RTqPCR/ELISA) of GLP-1/GLP-1R, SDF-1 $\alpha$ /CXCR4 and VIP/VPAC1, VPAC2, and PAC1 in 36 rats. Animals were divided into four groups and subjected to ischemia $(60 \mathrm{~min}$ ) and reperfusion $(24 \mathrm{~h})$ with or without pretreatment with sitagliptin $(5 \mathrm{mg} / \mathrm{kg}$ ) (IR and SIR) or sham-operated with or without sitagliptin pretreatment (controls and sitagliptin). $\mathrm{PGI}_{2}, \mathrm{PGE}_{2}$, and 13,14-dihydro-PGE 1 were significantly upregulated in IR but not SIR, while sitagliptin upregulated $\mathrm{PGD}_{2}$ and 15-deoxy-12,14$\mathrm{PGJ}_{2}$. IR and sitagliptin non-significantly upregulated GLP-1 while Glp1r expression was borderline detectable. VIP concentration and Vpac2 expression were downregulated in IR but not SIR, while Vpac1 was significantly downregulated solely in SIR. IRI upregulated both CXCR4 expression and concentration, and sitagliptin pretreatment abrogated receptor overexpression and downregulated Sdf1. In conclusion, hepatic IRI is accompanied by an elevation in proinflammatory prostanoids and overexpression of CXCR4, combined with downregulation of VIP/VPAC2. Beneficial effects of sitagliptin during hepatic IRI might be mediated by drug-induced normalization of proinflammatory prostanoids and upregulation of $\mathrm{PGD}_{2}$ and by concomitant downregulation of SDF- $1 \alpha / C X C R 4$ and reinstating VIP/VCAP2 signaling.
\end{abstract}

Keywords: drug repurposing; incretins; prostaglandins; vasoactive intestinal peptide (VIP); stromal-derived factor $1 \alpha$ (SDF-1 $\alpha$ ); glucagon-like peptide 1 (GLP-1); dipeptidyl peptidase IV (DPP4); gliptins; liver transplantation; hepatoprotection

\section{Introduction}

Liver transplantation is a life-saving procedure for patients with end-stage liver disease, the incidence of which is rising along with the increasing prevalence of its risk factors such as alcoholic and non-alcoholic steatohepatitis, viral infections, and cancer. While procedure frequency is constantly increasing as well, the number of patients requiring transplant exceeds the organ availability. Transplantation is associated with a significant 
risk of graft rejection, and an ischemia/reperfusion (IR) injury during transplantation is one of the key contributors. Moreover, the IR has a negative impact on the functioning of transplanted organs [1,2].

The IR injury is a complex phenomenon, and its pathology is not fully elucidated. A better understanding of its cellular and molecular mechanisms is needed to develop strategies protecting organs during and after transplantation [1,2]. Ischemia causes metabolic imbalance characterized by acidosis and ATP depletion, inducing apoptosis. Unfavorable changes in this phase intensify in the course of reperfusion. Activation of Kupffer cells and infiltration with $\mathrm{T}$ lymphocytes during the early phase of reperfusion and accumulation of macrophages and neutrophils during the late phase leads to the release of a plethora of inflammatory and immune mediators and generation of molecule-damaging reactive oxygen and nitrogen species [2].

IR event is accompanied by a release of vast amounts of arachidonic acid, an eicosanoid, from membrane phospholipids by phospholipase A2 (PLA2). Arachidonic acid is further converted to $\mathrm{PGH}_{2}$ by two isoforms of cyclooxygenase (COX), a constitutive COX1 and an inducible COX2. Subsequently, $\mathrm{PGH}_{2}$ is metabolized to prostacyclin $\mathrm{PGI}_{2}$, prostaglandins (PGs) $\mathrm{D}_{2}, \mathrm{E}_{2}$, and $\mathrm{F}_{2}$, and thromboxane (TX) $\mathrm{A}_{2}$, referred to as prostanoids. The 5-lipoxygenase, in turn, converts arachidonic acid into leukotriene (LT) $\mathrm{A}_{4}$. Less abundant dihomo- $\gamma$-linolenic acid, also metabolized by COX enzymes, becomes a precursor of series 1 of prostanoids, e.g., $\mathrm{PGE}_{1}$ [3]. Eicosanoids are frequently their own functional antagonists and display diverse biological activities, depending on their source, cell type, partner downstream receptors, and the context. Simplifying, COX1-derived prostanoids are mostly involved in housekeeping functions, while COX2-derived mediators are engaged in immune and inflammatory responses [4].

Hepatic IR is associated with the upregulated activity of PLA2 and COX2 and the accumulation of $\mathrm{PGE}_{2}$, produced mainly by hepatocytes and endothelial and Kupffer cells (reviewed in the work of [5]). However, the role of $\mathrm{PGE}_{2}$, a main proinflammatory prostanoid [3,4], in hepatic IR remains controversial. On the one hand, COX depletion [6] or inhibition by aspirin [7] protects the liver during IR. Consistently, inhibition of upstream PLA2 by dexamethasone [7,8] or downstream inducible PGE $_{2}$ synthase (mPGES-1) [9] confers protection as well. On the other, mesenchymal stem cell-derived $\mathrm{PGE}_{2}$ [10] or $\mathrm{PGE}_{2}$ signaling via $\mathrm{EP}_{4}$ receptor [11] are claimed to exert hepatoprotective effects during liver injury.

Apart from steroidal and non-steroidal anti-inflammatory drugs, the efficacy of other well-established pharmaceuticals in alleviating organ IR injury is currently being investigated. Among these, gliptins (dipeptidyl peptidase-4 (DPP-4) inhibitors and primarily antidiabetics) arouse a growing interest. Gliptins, including their protagonist, sitagliptin, have been shown to exert cytoprotective effects in animal models of hepatic [12-18], cardiac [19,20], renal [21-23], cerebral [24], testicular [25], and intestinal [26,27] IR injury. Although anti-inflammatory, antioxidant, and antiapoptotic properties of gliptins seem to be implicated, the underlying molecular mechanisms are to be explained.

This work was designed to evaluate the effect of IR injury and sitagliptin on rat liver profile of eicosanoids: 6-ketoPGF $1 \alpha$, a stable metabolite of $\mathrm{PGI}_{2} ; \mathrm{PGE}_{2} ; \mathrm{PGD}_{2} ; \mathrm{PGF}_{2}$; 15-deoxy-12,14-PGJ 2 , a $\mathrm{PGD}_{2}$ metabolite; 13,14-dihydro- $\mathrm{PGE}_{1}$, a $\mathrm{PGE}_{1}$ metabolite; $\mathrm{TXB}_{2}$, a stable metabolite of $\mathrm{TXA}_{2}$; and $\mathrm{LTB}_{4}$, a stable $\mathrm{LTA}_{4}$ metabolite, in the wide context of inflammatory mediators and oxidative, nitrosative, and halogenative stress markers. It was also aimed at analyzing the IR and sitagliptin impact on the expression and/or concentration of potentially relevant substrates of DPP-4 and their receptors, namely, SDF1/CXCR4, GLP1/GLP1R and VIP/VPAC1 and VPAC2, and PAC1.

\section{Results}

\subsection{A Rat Model of IR and Its Validation}

A rat IR model has previously been established [15,16], in which 36 animals were randomized into four groups: sham-operated (controls; $n=9$ ), sham-operated following 
pretreatment with sitagliptin ( $5 \mathrm{mg} / \mathrm{kg}$ p.o.) (sitagliptin; $n=8)$, subjected to IR procedure (IR; $n=9$ ), and subjected to IR procedure following pretreatment with sitagliptin (SIR; $n=10$ ). It was validated by an elevation in the activity of alanine (ALT) and aspartate (AST) aminotransferases following injury, less pronounced in SIR than the IR group. The repeated-measures ANOVA indicated significant effect of factor (time of blood collection: 0 , 2,6 , and $24 \mathrm{~h}$ ), group (control, IR, sitagliptin, SIR) as well as factor $\times$ group interaction on ALT and AST dynamics (Figure 1). In addition, histopathological analysis indicated slight necrotic changes as well as neutrophil infiltration in IR and SIR animals and a significantly higher degree of steatosis in animals pretreated with sitagliptin [16] (Supplementary Figures S1-S4).

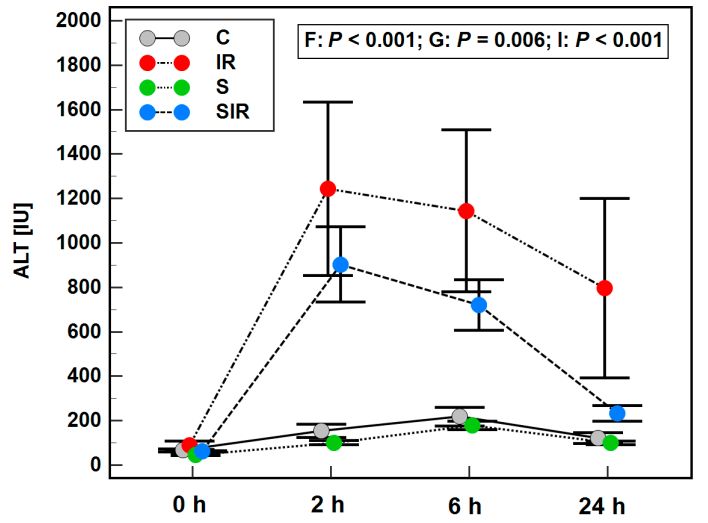

(a)

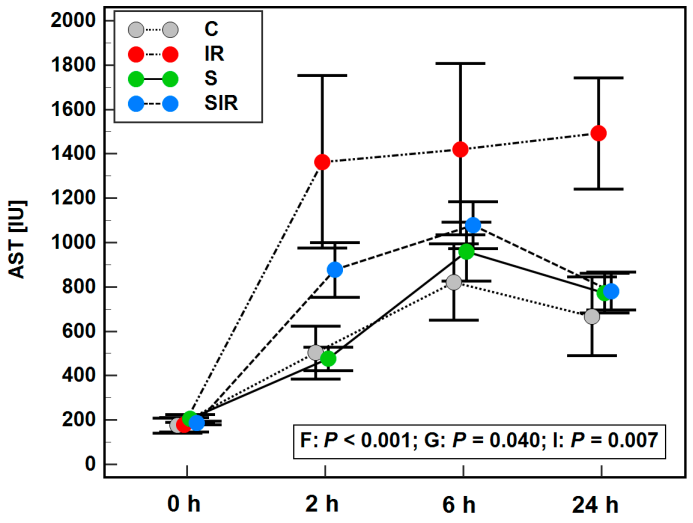

(b)

Figure 1. Validation of hepatic ischemia-reperfusion model—the effect of injury on the dynamics of liver enzymes: (a) alanine aminotransferase (ALT); (b) aspartate aminotransferase. Data are presented as mean \pm SEM and were analyzed using repeated-measures ANOVA. F, the effect of factor (time of blood sampling after IR); G, the effect of group (C, IR, $\mathrm{S}, \mathrm{SIR})$; I, the effect of factor $\times$ group interaction; $\mathrm{C}$, control sham-operated animals; IR, animals subjected to ischemiareperfusion; $S$, sham-operated animals pretreated with sitagliptin; SIR, animals subjected to ischemia-reperfusion pretreated with sitagliptin.

\subsection{Effect of IR Injury and Sitagliptin on Liver Profile of Eicosanoids}

The profile of eicosanoids was determined using liquid chromatography-tandem mass spectrometry (LC-MS/MS).

The concentrations of 6-ketoPGF $1 \alpha\left(\mathrm{PGI}_{2}\right), \mathrm{PGE}_{2}$, and 13,14-dihydro-PGE 1 in the liver were significantly upregulated in the IR group as compared to controls and IR animals pretreated with sitagliptin (SIR group). In addition, 6-ketoPGF $1 \alpha\left(\mathrm{PGI}_{2}\right)$, but not PGE 2 and 13,14-dihydro-PGE 1 , were also upregulated in the sitagliptin group as compared to controls and SIR animals (Table 1 ).

Table 1. Liver profile of eicosanoids—effect of IR injury and sitagliptin.

\begin{tabular}{|c|c|c|c|c|c|}
\hline \multirow{2}{*}{ Metabolite } & \multicolumn{4}{|c|}{ Median Prostanoid Concentration (pg/mg) (IQR) } & \multirow{2}{*}{$p$} \\
\hline & Control, $n=9$ & $\mathrm{IR}, n=9$ & $\mathrm{SIR}, n=10$ & Sitagliptin, $n=8$ & \\
\hline 6-ketoPGF $F_{1 \alpha}\left(\mathrm{PGI}_{2}\right)$ & $68.0(72.5)^{2,4}$ & $247.5(70.5)^{1,3}$ & $121.8(48.3)^{2,4}$ & $211(141.5)^{1,3}$ & 0.001 \\
\hline $\mathrm{PGE}_{2}$ & $154.7(127)^{2}$ & $263.3(74.4)^{1,3}$ & $184.7(39)^{2}$ & $225.4(160)$ & 0.050 \\
\hline $\mathrm{PGF}_{2}$ & $58.7(35.5)$ & $55.1(17.7)$ & $57.4(27.7)$ & $62.4(25.8)$ & 0.962 \\
\hline $\mathrm{PGD}_{2}$ & $571(849)^{4}$ & $1142(434)^{4}$ & $1180(493)^{4}$ & $1555(144)^{1,2,3}$ & 0.002 \\
\hline 15-deoxy-12,14-PGJ $2\left(\mathrm{PGD}_{2}\right)$ & $1.04(1.47)^{3,4}$ & $1.15(1.87)^{3,4}$ & $2.88(2.48)^{1,2}$ & $3.2(1.23)^{1,2}$ & 0.004 \\
\hline 13,14-dihydro-PGE 1 (PGE 1$)$ & $0.066(0.11)^{2}$ & $0.15(0.12)^{1,3}$ & $0.053(0.06)^{2}$ & $0.082(0.10)$ & 0.043 \\
\hline $\mathrm{TXB}_{2}\left(\mathrm{TXA}_{2}\right)$ & $6.19(4.42)$ & $3.6(2.85)$ & $3.44(5.0)$ & $4.61(3.0)$ & 0.559 \\
\hline $\mathrm{LTB}_{4}\left(\mathrm{LTA}_{4}\right)$ & $41.9(102)$ & $136.2(66.9)$ & $90.6(124.1)$ & $124.1(102.5)$ & 0.495 \\
\hline 6-ketoPGF $1 \alpha\left(\mathrm{PGI}_{2}\right) / \mathrm{TXB}_{2}\left(\mathrm{TXA}_{2}\right)$ & $15.7(34.4)^{2,4}$ & $75.2(72.9)^{1,3}$ & $21.6(45.4)^{2}$ & $46.3(39.2)^{1}$ & 0.015 \\
\hline
\end{tabular}

Data were analyzed using Kruskal-Wallis $H$ test with Conover post-hoc analysis and are presented as medians with IQR. ${ }^{1}$, significantly different from the control group; ${ }^{2}$, significantly different from IR group; ${ }^{3}$, significantly different from SIR group; ${ }^{4}$, significantly different from sitagliptin group. IQR, interquartile range; $n$, number of observations; IR, ischemia-reperfusion; SIR, sitagliptin pretreatment, and ischemia-reperfusion. Metabolite precursors are given in brackets. 
Sitagliptin significantly upregulated $\mathrm{PGD}_{2}$, which was higher than in controls, IR, and SIR animals. It also upregulated 15-deoxy-12,14-PGJ 2 , which was elevated in sitagliptin and SIR groups as compared to controls and IR animals (Table 1).

Liver concentrations of $\mathrm{PGF}_{2}, \mathrm{TBX}_{2}$, and $\mathrm{LTB}_{4}$ were affected neither by IR nor sitagliptin. The $\mathrm{PGI}_{2}$-to-TXA 4 ratio, calculated based on their stable metabolites (6-ketoPGF ${ }_{1 \alpha} / \mathrm{TXB}_{2}$ ), was higher in IR as compared to controls and SIR, but sitagliptin alone also elevated the ratio as compared to control animals (Table 1).

\subsection{Effect of IR Injury and Sitagliptin on Liver Expression of CXCR4/SDF1}

The expression and concentration of SDF1 cytokine and CXCR4, its receptor, were determined using reversely transcribed quantitative polymerase chain reaction (RTqPCR) and immunoenzymatic assays (ELISA).

The IR significantly upregulated CXCR4, both at mRNA and protein level, and pretreatment with sitagliptin downregulated its expression and concentration. Regarding the CXCR4 ligand SDF1, its expression (Sdf1) was significantly lower in the SIR group as compared to IR and controls. Neither IR nor sitagliptin had a significant impact on SDF1 $\alpha$ (Figure 2).

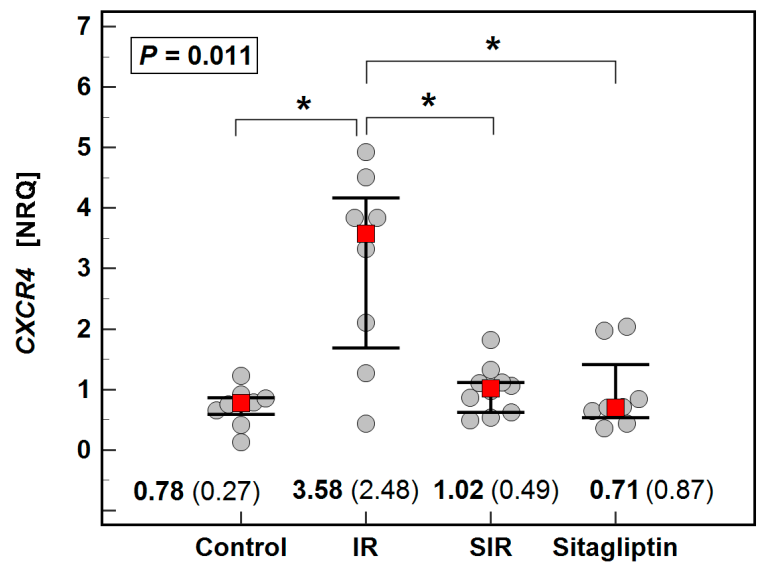

(a)

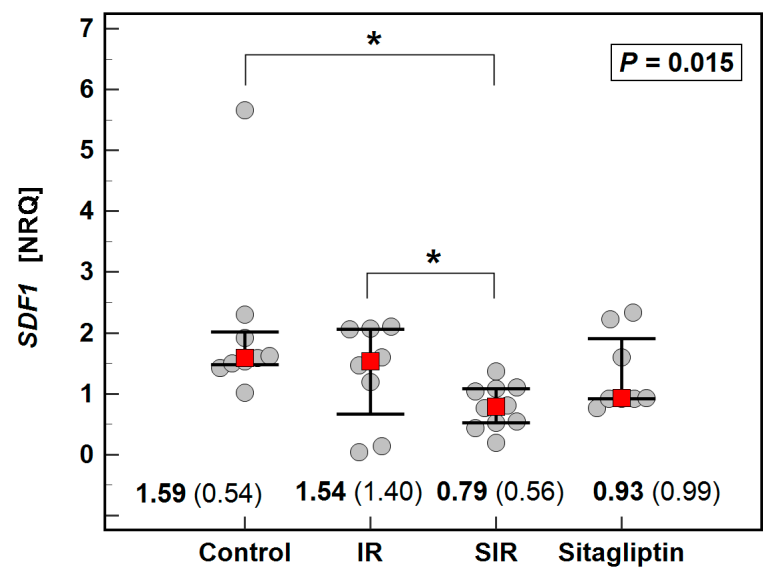

(c)

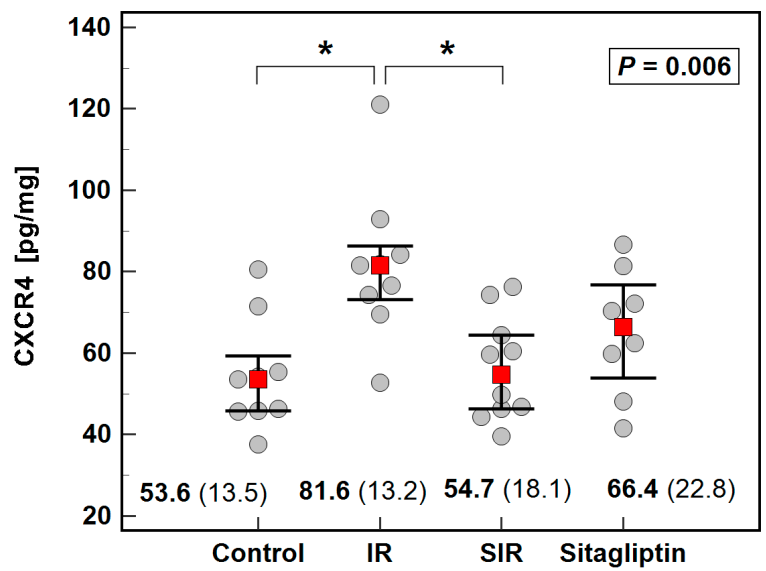

(b)

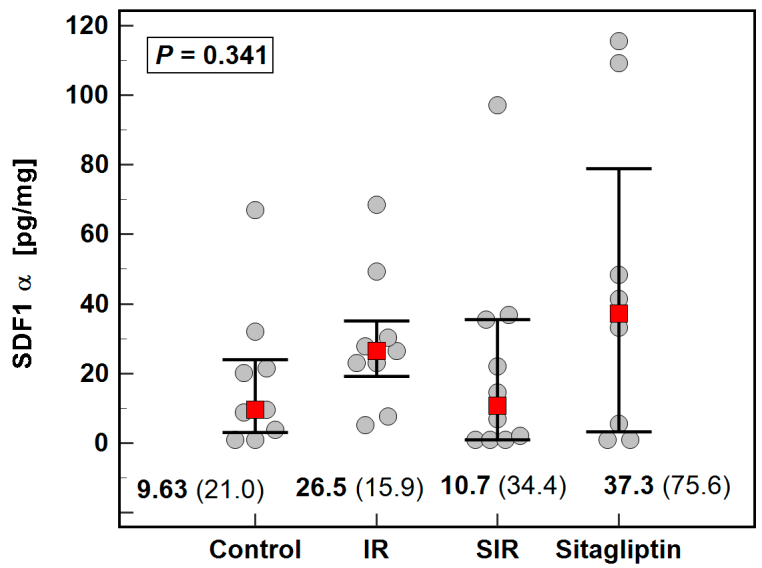

(d)

Figure 2. Effect of IR injury and sitagliptin on CXCR4/SDF1 axis in the liver: (a) Cxcr4 expression; (b) CXCR4 concentration; (c) Sdf1 expression; (d) SDF1 $\alpha$ concentration. Data were analyzed using the Kruskal-Wallis $H$ test and are presented as medians with IQR (red squares with whiskers and numbers below dot-plots). Significant $(p<0.05)$ differences between groups, identified in post-hoc analysis (Conover test), are indicated by connectors with * symbol. NRQ, normalized relative quantity; IR, ischemia-reperfusion; SIR, sitagliptin pretreatment and ischemia-reperfusion; IQR, interquartile range. 


\subsection{Effect of IR Injury and Sitagliptin on Liver Expression of PAC1, VPAC1, VPAC2/VIP}

The IR significantly downregulated the expression of $V p a c 2$ and concentration of VIP while pretreatment with sitagliptin prevented the downregulation of both the receptor expression and ligand concentration. The IR non-significantly downregulated Pac1 and Vpac1, the expression of which was more markedly downregulated in SIR animals, significantly so in the case of Vpac1 expression (Figure 3).

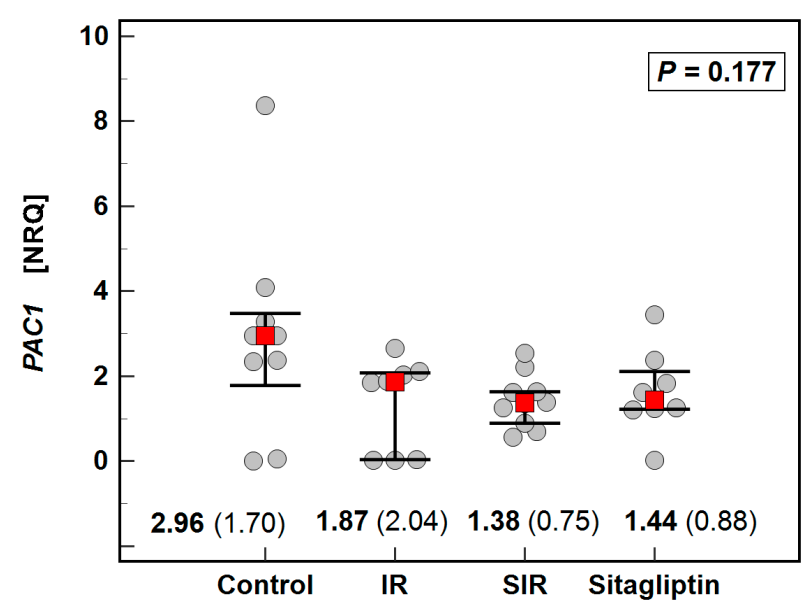

(a)

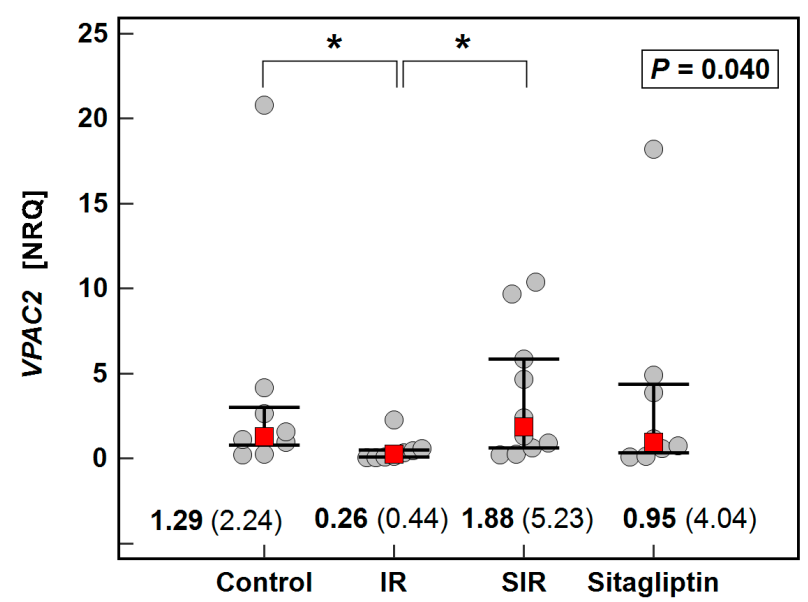

(c)

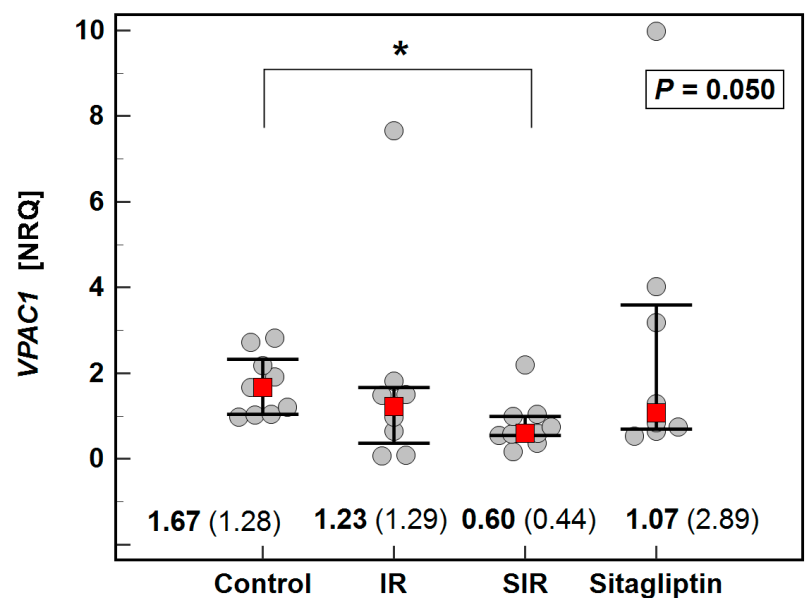

(b)

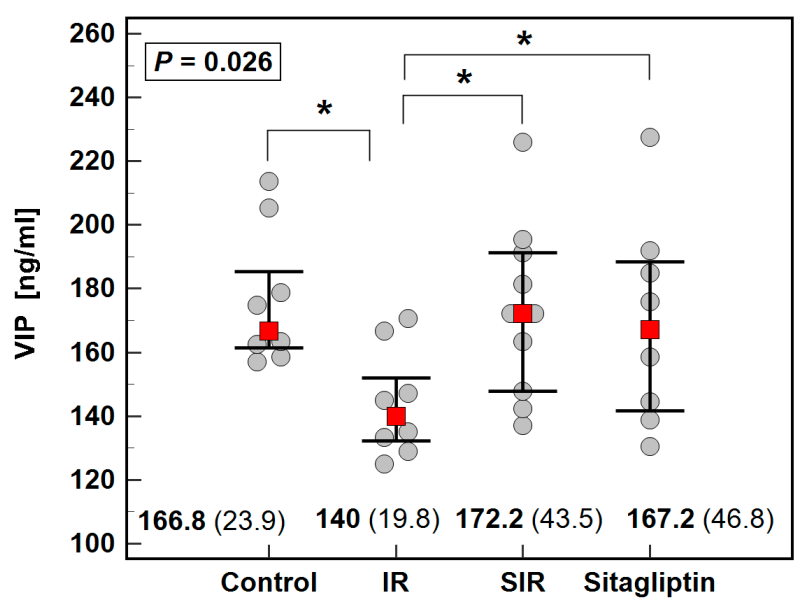

(d)

Figure 3. Effect of IR injury and sitagliptin on PAC1, VPAC1, VPAC2/VIP axis in the liver: (a) Pac1 expression; (b) Vpac1 expression; (c) Vpac2 expression; (d) VIP concentration. Data were analyzed using the Kruskal-Wallis $H$ test and are presented as medians with IQR (red squares with whiskers and numbers below dot-plots). Significant $(p<0.05)$ differences between groups, identified in post-hoc analysis (Conover test), are indicated by connectors with * symbol. NRQ, normalized relative quantity; IR, ischemia-reperfusion; SIR, sitagliptin pretreatment and ischemia-reperfusion; IQR, interquartile range.

\subsection{Effect of IR Injury and Sitagliptin on Liver Expression of GLP1R/GLP1}

Neither IR nor sitagliptin had a significant impact on Glp1r expression and GLP1 concentration in the liver (Figure 4). 


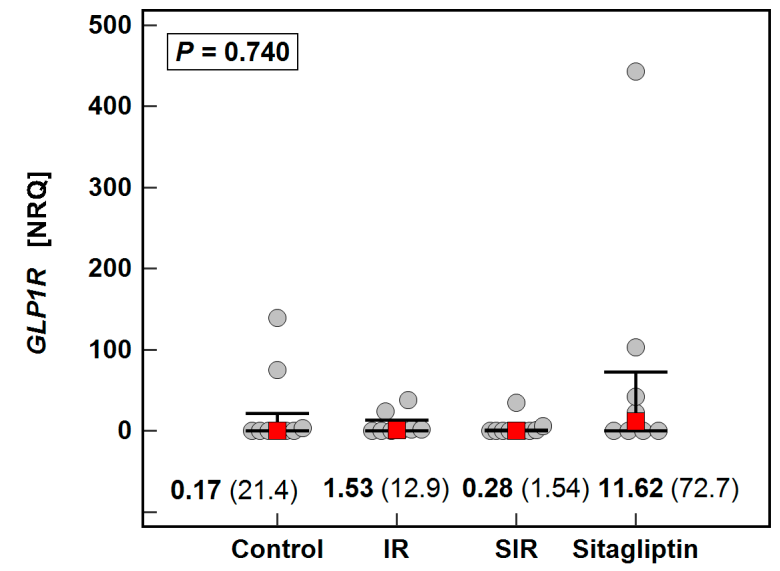

(a)

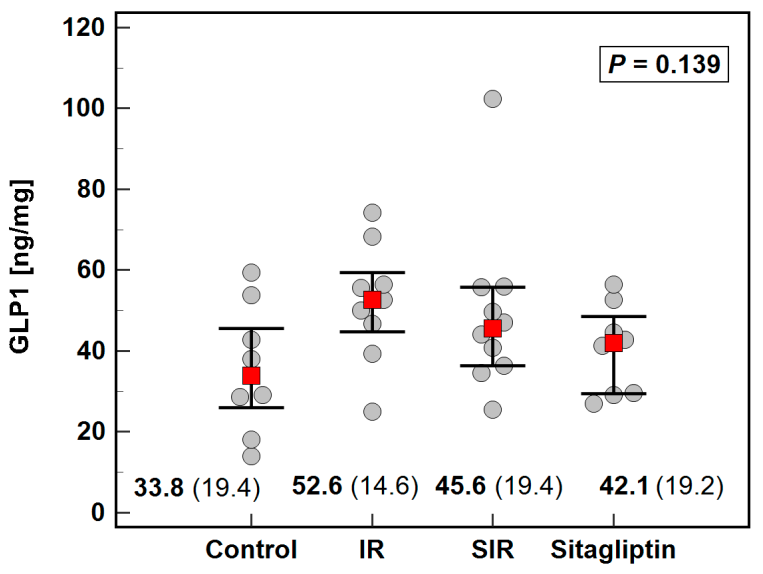

(b)

Figure 4. Effect of IR injury and sitagliptin on GLP1R/GLP1 axis in the liver: (a) Glp1r expression; (b) GLP1 concentration. Data were analyzed using the Kruskal-Wallis $H$ test and are presented as medians with IQR (red squares with whiskers and numbers below dot-plots). NRQ, normalized relative quantity; IR, ischemia-reperfusion; SIR, sitagliptin pretreatment and ischemia-reperfusion; IQR, interquartile range.

2.6. Relationship between Eicosanoids, DPP4 Ligands, and Their Receptors, and Mediators of Inflammation and Oxidative, Nitrosative, and Halogenative Stress (Univariate Analysis)

Liver eicosanoids as well as investigated DPP4 ligands and their receptors were related to the expression or concentration of mediators of inflammation and oxidative, nitrosative and halogenative stress: IL-1 $\beta$, IL-10, IFN $\gamma$, VEGF-A, MIP-2, TNF $\alpha$, Il6, Mmp1, Nampt, Tnfa, Nox1, Nox2, Nox4, Mdk, Ptn, 3-nitrotyrosine (NT), and 3-bromotyrosine (BT).

\subsubsection{Eicosanoids}

In univariate analysis, 6-ketoPGF $1 \alpha\left(\mathrm{PGI}_{2}\right)$ correlated with the concentration of 13,14dihydro-PGE $1(r=0.36, p=0.031), \mathrm{LBT}_{4}(r=0.35, p=0.035), \mathrm{PGD}_{2}(r=0.45, p=0.006), \mathrm{PGE}_{2}$ $(r=0.61, p<0.001), \mathrm{CXCR} 4(r=0.55, p<0.001), 3-\mathrm{NT}(r=0.38, p=0.021), \mathrm{SDF} 1 \alpha(r=0.40$, $p=0.016)$, VIP $(\rho=-0.51, p=0.002)$, and IL-1 $\beta(r=0.33, p=0.049)$ and the expression of Nox4 ( $r=-0.67, p<0.001)$, Ptn $(r=-0.38, p=0.023)$, Sdf1 $(r=-0.44, p=0.009)$, Vpac2 $(r=-0.38, p=0.026), \operatorname{Vpac1}(r=-0.34, p=0.045)$, and Cxcr4 $(r=0.48, p=0.003)$.

Apart from 6-ketoPGF $1 \alpha\left(\mathrm{PGI}_{2}\right)$, the concentration of $\mathrm{PGE}_{2}$ corelated with $\mathrm{LBT}_{4}$ $(r=0.64, p<0.001), \mathrm{PGD}_{2}(r=0.55, p<0.001), \mathrm{PGF}_{2}(r=0.69, p<0.001), \mathrm{CXCR}_{4}(r=0.34$, $p=0.043), \operatorname{SDF} 1 \alpha(r=0.54, p<0.001)$, and VIP $(r=-0.42, p=0.010)$ and the expression of $\operatorname{Nox} 4(r=-0.42, p=0.012)$ and Cxcr4 $(r=0.43, p=0.011)$.

Apart from $\mathrm{PGE}_{2}$, the concentration of $\mathrm{PGF}_{2}$ correlated with these of $\mathrm{LTB}_{4}(r=0.42$, $p=0.010), \mathrm{TXB}_{2}(r=0.59, p<0.001), \mathrm{PGD}_{2}(r=0.36, p=0.033)$, and SDF1 $\alpha(r=0.41$, $p=0.012)$.

In addition to 6-ketoPGF $1 \alpha\left(\mathrm{PGI}_{2}\right), \mathrm{PGE}_{2}$, and $\mathrm{PGF}_{2}$, the concentration of $\mathrm{PGD}_{2}$ corelated with 15-deoxy-12,14-PGJ $(r=0.56, p<0.001), \mathrm{LBT}_{4}(r=0.59, p<0.001)$, and $\operatorname{SDF} 1 \alpha(r=0.59, p<0.001)$.

Apart from $\mathrm{PGD}_{2}$, the concentration of 15-deoxy-12,14-PGJ 2 correlated with that of $\operatorname{LTB}_{4}(r=0.44, p=0.009)$.

The 13,14-dihydro-PGE 1 correlated solely with 6-ketoPGF $1 \alpha\left(\mathrm{PGI}_{2}\right)$.

Apart from $\mathrm{PGF}_{2}$, the concentration of $\mathrm{TXB}_{2}$ correlated with the expression of Nox2 $(r=-0.36, p=0.035)$.

In addition to prostanoids: 15-deoxy-12,14-PGJ $2, \mathrm{PGI}_{2}, \mathrm{PGD}_{2}, \mathrm{PGE}_{2}$, and $\mathrm{PGF}_{2}$, the concentration of $\mathrm{LBT}_{4}$ correlated with that of SDF1 $\alpha(r=0.59, p<0.001)$. 


\subsubsection{CXCR4/SDF1}

The concentration of CXCR4 correlated with that of $\mathrm{PGE}_{2}$ and 6-ketoPGF $1 \alpha\left(\mathrm{PGI}_{2}\right)$ and the expression of Cxcr4 $(r=0.48, p=0.004)$ and Vpac2 $(r=-0.40, p=0.019)$. The receptor expression (Cxcr4) correlated with the expression of Nox4 $(r=-0.34, p=0.044)$ and Il6 $(r=0.40, p=0.018)$ and GLP1 concentration $(r=0.34, p=0.046)$, in addition to CXCR4 protein and the concentrations of 6-ketoPGF $1 \alpha\left(\mathrm{PGI}_{2}\right)$ and $\mathrm{PGE}_{2}$.

The concentration of SDF1 $\alpha$ correlated with that of 6-ketoPGF $1 \alpha\left(\mathrm{PGI}_{2}\right), \mathrm{PGD}_{2}, \mathrm{PGE}_{2}$, $\mathrm{PGF}_{2}$, and $\mathrm{LTB}_{4}$. Ligand expression (Sdf1), in turn, correlated with the concentration of 6ketoPGF $_{1 \alpha}\left(\mathrm{PGI}_{2}\right)$ and IL-1 $\beta(r=-0.36, p=0.034)$ and the expression of $M d k$ $(r=0.41, p=0.014), \operatorname{Ptn}(r=0.70, p<0.001)$, Nox1 $(r=0.38, p=0.027)$, Nox4 $(r=0.53$, $p=0.001), \operatorname{Vpac1}(r=0.79, p<0.001), \operatorname{Mmp} 1(r=0.51, p=0.002)$, and Nampt $(r=0.68$, $p<0.001)$.

\subsubsection{PAC1, VPAC1, VPAC2/VIP}

The expression of Vpac1 correlated with 6-ketoPGF ${ }_{1 \alpha}\left(\mathrm{PGI}_{2}\right)$ concentration and the expression of Sdf1, Glp1r $(r=0.69, p<0.001), \operatorname{Mdk}(r=0.79, p<0.001), \operatorname{Ptn}(r=0.87$, $p<0.001)$, Nox1 $(r=0.73, p<0.001)$, Nox2 $(r=-0.43, p=0.009), \operatorname{Mmp} 1(r=0.80, p<0.001)$, Nampt $(r=0.53, p=0.001)$, and Tnfa $(r=0.37, p=0.029)$.

The expression of Vpac2 correlated with liver concentrations of CXCR4, 6-ketoPGF $1 \alpha$ $\left(\mathrm{PGI}_{2}\right)$, and GLP1 $(r=-0.37, p=0.030)$, whereas the expression of Pac1 did not show any significant correlation.

The concentration of VIP correlated with 6-ketoPGF $1 \alpha\left(\mathrm{PGI}_{2}\right), \mathrm{PGE}_{2}$, and 3-BT $(r=-0.33, p=0.049)$ and the expression of Nox4 $(r=0.40, p=0.017)$.

\subsubsection{GLP1R/GLP1}

The expression of Glp1r correlated with these of Vpac1, Mdk $(r=0.84, p<0.001)$, Ptn $(r=0.68, p<0.001)$, Nox1 $(r=0.90, p<0.001)$, Nox2 $(r=-0.43, p=0.011)$, Il6 $(r=0.47$, $p=0.004)$, Tnfa $(r=0.71, p<0.001)$, and Mmp1 $(r=0.83, p<0.001)$.

GLP1 correlated with IFN $\gamma(r=-0.37, p=0.025)$ in addition to Cxcr4 and Vpac2 expression.

\subsection{Independent Predictors of Liver Eicosanoids and DPP4 Ligands and Their Receptors (Multivariate Analysis)}

Multiple linear regression analysis (stepwise method) was conducted to discern independent predictors of variability in the concentration of individual eicosanoids as well as concentration/expression of investigated DPP4 ligands and their receptors.

\subsubsection{Independent Predictors of Liver Eicosanoids}

Of the variables found significantly associated in univariate analysis, 13,14-dihydro$\mathrm{PGE}_{1}, \mathrm{PGE}_{2}$, 3-NT, VIP, IL-1 $\beta$, Cxcr4, and Nox4 were independent predictors of 6-ketoPGF $1 \alpha$ $\left(\mathrm{PGI}_{2}\right)$, explaining $83 \%$ variability in its concentration.

6-ketoPGF ${ }_{1 \alpha}\left(\mathrm{PGI}_{2}\right), \mathrm{PGF}_{2}$, and $\mathrm{LTB}_{4}$ were independent predictors of $\mathrm{PGE}_{2}$, explaining $74 \%$ of variability, and $\mathrm{PGE}_{2}$ and $\mathrm{TXB}_{2}$ were independent predictors of $\mathrm{PGF}_{2}$, explaining $61 \%$ in its variability. $\mathrm{PGF}_{2}$ was independently associated with $\mathrm{TXB}_{2}$, explaining $28 \%$ in its variability, and 15-deoxy-12,14-PGJ $2, \mathrm{PGE}_{2}$, and $\mathrm{SDF} 1 \alpha$ were independent predictors of $\mathrm{LTB}_{4}$, explaining $62 \%$ in its variability.

The IR was a sole predictor of 13,14-dihydro-PGE 1 , which explained $16 \%$ in concentration variability. Sitagliptin was an independent predictor of 15-deoxy-12,14- $\mathrm{PGJ}_{2}$, which, together with $\mathrm{PGD}_{2}$, explained $45 \%$ in concentration variability and of $\mathrm{PGD}_{2}$, for which it explained $73 \%$ of variability together with $15-$ deoxy-12,14-PGJ $2, \mathrm{PGE}_{2}$, and SDF1 $\alpha$ (Table 2). 
Table 2. Regression models explaining variability in the liver concentration of eicosanoids.

\begin{tabular}{|c|c|c|c|c|c|}
\hline Dependent Variable & Explanator Variables & $\begin{array}{c}\text { Regression } \\
\text { Coefficient }(\beta), p\end{array}$ & $r_{\mathrm{p}}$ & VIF & $\mathbf{R}^{2}$; ANOVA \\
\hline \multirow{8}{*}{ 6-ketoPGF ${ }_{1 \alpha}\left(\mathrm{PGI}_{2}\right)$} & (Constant) & 100.4 & & & \multirow{8}{*}{$\begin{array}{c}\mathrm{R}^{2}=0.832 ; F=19.1, \\
p<0.0001\end{array}$} \\
\hline & 13,14-dihydro-PGE 1 & $321.3, p=0.003$ & 0.53 & 1.07 & \\
\hline & $\mathrm{PGE}_{2}$ & $0.26, p=0.028$ & 0.41 & 1.63 & \\
\hline & Cxcr4 (log) & $56.7, p=0.022$ & 0.42 & 1.32 & \\
\hline & 3-NT & $1.56, p<0.001$ & 0.64 & 1.18 & \\
\hline & Nox4 (log) & $-22.0, p=0.055$ & -0.36 & 1.64 & \\
\hline & VIP & $-0.73, p=0.025$ & -0.42 & 1.39 & \\
\hline & IL-1 $\beta$ & $0.07, p=0.002$ & 0.55 & 1.21 & \\
\hline \multirow{4}{*}{$\mathrm{PGE}_{2}$} & (Constant) & 23.11 & & & \multirow{4}{*}{$\begin{array}{c}\mathrm{R}^{2}=0.744 ; F=30.0, \\
p<0.0001\end{array}$} \\
\hline & 6-ketoPGF ${ }_{1 \alpha}\left(\mathrm{PGI}_{2}\right)$ & $0.33, p<0.001$ & 0.57 & 1.17 & \\
\hline & $\mathrm{PGF}_{2}$ & $1.57, p<0.001$ & 0.63 & 1.26 & \\
\hline & $\mathrm{LTB}_{4}$ & $0.33, p=0.006$ & 0.47 & 1.33 & \\
\hline \multirow{3}{*}{$\mathrm{PGF}_{2}$} & (Constant) & 3.10 & & & \multirow{3}{*}{$\begin{array}{c}\mathrm{R}^{2}=0.613 ; F=26.1, \\
p<0.0001\end{array}$} \\
\hline & $\mathrm{PGE}_{2}$ & $0.18, p<0.001$ & 0.69 & 1.05 & \\
\hline & $\mathrm{TXB}_{2}(\log )$ & $33.9, p=0.002$ & 0.52 & 1.05 & \\
\hline \multirow{5}{*}{$\mathrm{PGD}_{2}$} & (Constant) & 126.7 & & & \multirow{5}{*}{$\begin{array}{c}\mathrm{R}^{2}=0.729 ; F=20.8, \\
p<0.0001\end{array}$} \\
\hline & 15-deoxy-12,14-PGJ 2 & $145.5, p<0.001$ & 0.59 & 1.10 & \\
\hline & $\mathrm{PGE}_{2}$ & $2.27, p=0.007$ & 0.46 & 1.40 & \\
\hline & SDF1 $\alpha$ & $4.86, p=0.026$ & 0.39 & 1.50 & \\
\hline & Sitagliptin & $405, p=0.005$ & 0.48 & 1.19 & \\
\hline \multirow{3}{*}{ 15-deoxy-12,14-PGJ 2} & (Constant) & 0.20 & & & \multirow{3}{*}{$\begin{aligned} \mathrm{R}^{2}= & 0.453 ; F=13.7 \\
& p<0.001\end{aligned}$} \\
\hline & $\mathrm{PGD}_{2}$ & $0.002, p<0.001$ & 0.60 & 1.00 & \\
\hline & Sitagliptin & $1.25, p=0.006$ & 0.45 & 1.00 & \\
\hline \multirow{2}{*}{ 13,14-dihydro-PGE 1} & (Constant) & 0.08 & & & \multirow{2}{*}{$\begin{array}{c}\mathrm{R}^{2}=0.161 ; F=6.54 \\
p=0.015\end{array}$} \\
\hline & IR & $0.07, p=0.015$ & 0.40 & 1.00 & \\
\hline \multirow{2}{*}{$\mathrm{TXB}_{2}(\log )$} & (Constant) & 0.24 & & & \multirow{2}{*}{$\begin{array}{c}\mathrm{R}^{2}=0.279 ; F=12.8 \\
p=0.001\end{array}$} \\
\hline & $\mathrm{PGF}_{2}$ & $0.01, p=0.001$ & 0.53 & 1.00 & \\
\hline \multirow{4}{*}{$\mathrm{LTB}_{4}$} & (Constant) & -42.2 & & & \multirow{4}{*}{$\begin{array}{c}\mathrm{R}^{2}=0.624 ; F=17.7, \\
p<0.0001\end{array}$} \\
\hline & 15-deoxy-12,14-PGJ 2 & $17.6, p=0.002$ & 0.50 & 1.02 & \\
\hline & $\mathrm{PGE}_{2}$ & $0.42, p=0.001$ & 0.53 & 1.40 & \\
\hline & SDF1 $\alpha$ & $0.72, p=0.027$ & 0.38 & 1.42 & \\
\hline
\end{tabular}

Data were analyzed using the stepwise method of linear multivariate regression. Variables found significantly associated with dependent variables were entered into the analysis. Results are presented as regression coefficients $\beta$ together with corresponding $p$-value and partial correlation coefficient $\left(r_{\mathrm{p}}\right)$ for each explanatory variable retained in the regression model and as the model's coefficient of determination $\left(\mathrm{R}^{2}\right)$ together with ANOVA results ( $F$ statistics and $p$-value). VIF, variable inflation factor.

\subsubsection{Independent Predictors of Liver Expression of DPP4 Ligands and Their Receptors}

The IR was an independent predictor of the concentration of CXCR4, explaining 39\% of its variability together with 6-ketoPGF $1 \alpha\left(\mathrm{PGI}_{2}\right)$ and the concentration of VIP, explaining $39 \%$ of its variability together with $\mathrm{PGE}_{2}$ and $3-\mathrm{BT}$. Together with IFN $\gamma$, it also explained $32 \%$ of the variability in GLP1 concentration. The IR was a sole predictor of Cxcr4 and Vpac2 expression, explaining, respectively, $38 \%$ and $23 \%$ in their variability (Table 3 ).

The variability in SDF1 $\alpha$ concentration was explained in $44 \%$ by $\mathrm{LTB}_{4}$ and $\mathrm{PGD}_{2}$, while that in Sdf1 expression in $84 \%$ by changes in expression of Vpac1, Mdk, Nox4, and Nampt (Table 3).

The variability in the expression of the Vpac1 receptor was explained in $91 \%$ by changes in Mdk, Nox2, Ptn, and Sdf1 expression and this in Glp1r in 83\% by changes in Nox1 and Nox2 expression (Table 3). 
Table 3. Regression models explaining variability in the expression and/or concentrations of DPP4 ligands and their receptors.

\begin{tabular}{|c|c|c|c|c|c|}
\hline Dependent Variable & Explanatory Variables & $\begin{array}{c}\text { Regression } \\
\text { Coefficient }(\beta), p\end{array}$ & $r_{\mathrm{p}}$ & VIF & $\mathrm{R}^{2} ; \mathrm{ANOVA}$ \\
\hline CXCR4 & $\begin{array}{c}\text { (Constant) } \\
\text { 6-ketoPGF } \text {-kG }_{1 \alpha}\left(\mathrm{PGI}_{2}\right) \\
\text { IR }\end{array}$ & $\begin{array}{c}48.1 \\
0.07, p=0.034 \\
15.8, p=0.027\end{array}$ & $\begin{array}{l}0.36 \\
0.38\end{array}$ & $\begin{array}{l}1.31 \\
1.31\end{array}$ & $\begin{aligned} \mathrm{R}^{2}= & 0.390 ; F=10.2, \\
& p<0.001\end{aligned}$ \\
\hline Cxcr4 (log) & $\begin{array}{c}\text { (Constant) } \\
\text { IR }\end{array}$ & $\begin{array}{c}-0.11 \\
0.50, p<0.001\end{array}$ & 0.61 & 1.00 & $\begin{array}{c}\mathrm{R}^{2}=0.376 ; F=19.9 \\
p<0.0001\end{array}$ \\
\hline Sdf1 (log) & $\begin{array}{l}\text { (Constant) } \\
\text { Nox4 (log) } \\
\text { Vpac1 (log) } \\
\text { Nampt (log) }\end{array}$ & $\begin{array}{c}0.002 \\
0.16, p<0.001 \\
0.40, p<0.001 \\
0.62, p<0.001\end{array}$ & $\begin{array}{l}0.60 \\
0.65 \\
0.62\end{array}$ & $\begin{array}{l}1.13 \\
1.57 \\
1.41\end{array}$ & $\begin{array}{c}\mathrm{R}^{2}=0.817 ; F=46.1, \\
p<0.0001\end{array}$ \\
\hline SDF1 $\alpha$ & $\begin{array}{l}\text { (Constant) } \\
\mathrm{LTB}_{4} \\
\mathrm{PGD}_{2}\end{array}$ & $\begin{array}{c}-12.8 \\
0.16, p=0.028 \\
0.02, p=0.030\end{array}$ & $\begin{array}{l}0.37 \\
0.37\end{array}$ & $\begin{array}{l}1.54 \\
1.54\end{array}$ & $\begin{aligned} \mathrm{R}^{2}= & 0.436 ; F=12.7 \\
& p<0.001\end{aligned}$ \\
\hline Vpac1 (log) & $\begin{array}{l}\text { (Constant) } \\
\text { Mdk (log) } \\
\text { Nox2 (log) } \\
\text { Sdf1 (log) }\end{array}$ & $\begin{array}{c}0.003 \\
0.38, p<0.001 \\
-0.18, p=0.043 \\
0.62, p<0.001\end{array}$ & $\begin{array}{c}0.82 \\
-0.36 \\
0.83\end{array}$ & $\begin{array}{l}1.27 \\
1.13 \\
1.24\end{array}$ & $\begin{array}{c}\mathrm{R}^{2}=0.893 ; F=85.8 \\
p<0.0001\end{array}$ \\
\hline Vpac2 (log) & $\begin{array}{c}\text { (Constant) } \\
\text { IR } \\
\end{array}$ & $\begin{array}{c}0.17 \\
-0.78, p=0.004\end{array}$ & -0.48 & 1.00 & $\begin{array}{c}\mathrm{R}^{2}=0.231 ; F=9.88 \\
p=0.004\end{array}$ \\
\hline VIP & $\begin{array}{l}\text { (Constant) } \\
\text { PGE }_{2} \\
\text { 3-BT } \\
\text { IR }\end{array}$ & $\begin{array}{c}200.0 \\
-0.09, p=0.073 \\
-1.95, p=0.040 \\
-23.1, p=0.021\end{array}$ & $\begin{array}{l}-0.32 \\
-0.36 \\
-0.40\end{array}$ & $\begin{array}{l}1.13 \\
1.01 \\
1.12\end{array}$ & $\begin{array}{c}\mathrm{R}^{2}=0.388 ; F=6.55 \\
p=0.002\end{array}$ \\
\hline Glp1r (log) & $\begin{array}{l}\text { (Constant) } \\
\text { Nox1 (log) } \\
\text { Nox2 (log) }\end{array}$ & $\begin{array}{c}-0.02 \\
1.02, p<0.001 \\
-0.67, p=0.030\end{array}$ & $\begin{array}{c}0.89 \\
-0.37\end{array}$ & $\begin{array}{l}1.10 \\
1.10\end{array}$ & $\begin{array}{c}\mathrm{R}^{2}=0.829 ; F=77.3 \\
p<0.0001\end{array}$ \\
\hline GLP1 & $\begin{array}{l}\text { (Constant) } \\
\text { IFN } \gamma \\
\text { IR }^{1}\end{array}$ & $\begin{array}{c}49.9 \\
-0.004, p=0.019 \\
14.4, p=0.006\end{array}$ & $\begin{array}{c}-0.40 \\
0.47\end{array}$ & $\begin{array}{l}1.00 \\
1.00\end{array}$ & $\begin{array}{c}\mathrm{R}^{2}=0.315 ; F=7.37 \\
p=0.002\end{array}$ \\
\hline
\end{tabular}

Data were analyzed using the stepwise method of linear multivariate regression. Variables found significantly associated with dependent variables were entered into the analysis. Results are presented as regression coefficients $\beta$ together with corresponding $p$-value and partial correlation coefficient $\left(r_{\mathrm{p}}\right)$ for each explanatory variable retained in the regression model and as the model's coefficient of determination $\left(\mathrm{R}^{2}\right)$ together with ANOVA results ( $F$ statistics and $p$-value). IR, ischemia-reperfusion. ${ }^{1}$, IR and SIR groups combined to analyze the effect of the IR component. VIF, variable inflation factor.

\section{Discussion}

Deciphering molecular mechanisms of hepatic IR injury is a prerequisite to developing successful treatment strategies that would improve patients' survival by reducing rates of graft rejection and improving the function of transplanted organs [2]. The ATP depletion in sinusoidal endothelial cells and hepatocytes caused by ischemia leads to the generation of reactive oxygen species (ROS), cell death, and release of alarmins, activating resident neutrophils and Kupfer cells. Released ROS and cytokines damage macromolecules and recruit circulating immune cells as well as hepatic stellate cells, engaging them in selfperpetuating inflammation and oxidative stress [2]. Therefore, targeting oxidative stress, inflammation, and preventing apoptosis are viewed as promising therapeutic options.

Prostanoids are potent mediators of immune and inflammatory responses. Under physiological conditions, prostanoids maintain homeostasis and are hepatoprotective. However, both their depletion and excess, occurring as a consequence of COX-2 activation in response to insult, might be detrimental [28]. In the IR settings accompanied by reduction in prostanoids' concentration, a treatment with prostaglandins seems to be beneficial due to improved liver hemodynamics and survival of sinusoidal epithelial cells and reduced generation of ROS, leukocyte migration, and platelet aggregation (reviewed in the work 
of [29]). However, the efficacy of none of the tested prostaglandins, that is, $\mathrm{PGE}_{1}, \mathrm{PGE}_{2}$, or $\mathrm{PGI}_{2}$, has been confirmed in clinical trials [2]. Moreover, COX2 has been ascribed both a protective [30] and a critical enabling role in hepatic IR injury [6]. Adding to the confusion, COX2 inhibition [7] or inhibition of any other enzyme involved in the synthesis of eicosanoids [7-9] have proved beneficial.

In the IR injury model investigated here, hepatic concentrations of 13,14-dihydro$\mathrm{PGE}_{1}, 6$-keto-PGF $1 \alpha$, and $\mathrm{PGE}_{2}$ were elevated in IR as compared to sham-operated animals while these of $\mathrm{PGD}_{2}$, its metabolite 15 -deoxy-12,14-PGJ $2, \mathrm{PGF}_{2}, \mathrm{TXB}_{4}$, and $\mathrm{LTB}_{4}$ were not significantly altered. Similar IR-induced alterations in the profile of prostanoids were reported in the heart by Qiu et al. [31] and demonstrated to contribute to cardiac apoptosis. The authors have observed the upregulation of 6-keto-PGF ${ }_{1 \alpha}, \mathrm{PGE}_{2}, \mathrm{PGD}_{2}$ and no change in $\mathrm{TXB}_{2}$ and $\mathrm{PGF}_{2 \alpha}$ (13,14-dihydro-PGE 1,15 -deoxy-12,14-PGJ ${ }_{2}$, and $\mathrm{LTB}_{4}$ were not determined). The upregulation of $\mathrm{PGI}_{2}$ and an elevation of $\mathrm{PGI}_{2} / \mathrm{TXA}_{2}$ ratio have also characterized rat hippocamps in the course of cerebral IR injury but have been interpreted as a physiological mechanism aimed at neuroprotection [32].

The multivariate analysis conducted in the present study demonstrated that IR was an independent predictor of solely 13,14-dihydro-PGE ${ }_{1}$. However, 13,14-dihydro-PGE 1 was, in turn, an independent predictor of 6-ketoPGF $1 \alpha\left(\mathrm{PGI}_{2}\right)$, which explained variability in $\mathrm{PGE}_{2}$, a contributor to the variability in $\mathrm{PGF}_{2}, \mathrm{PGI}_{2}, \mathrm{PGD}_{2}$, and $\mathrm{LTB}_{4}$, stressing strong interrelationships between all studied eicosanoids. The stimulatory effect of inflammation and oxidative stress on their synthesis was indicated by the inclusion of IL-1 $\beta$ and 3-NT, an oxidative/nitrosative stress marker, in the regression models predicting prostacyclin 6ketoPGF $1 \alpha\left(\mathrm{PGI}_{2}\right)$ concentration as well as by including SDF-1 $\alpha$ or CXCR4 in the regression models explaining the variability in 6-ketoPGF $1 \alpha\left(\mathrm{PGI}_{2}\right), \mathrm{PGD}_{2}$, and $\mathrm{LTB}_{4}$ concentration.

There is an increasing interest in repurposing the well-established drugs with already known toxicity, pharmacokinetics, and pharmacodynamics [33], including repositioning gliptins for IR injury. The contribution of antioxidant, anti-inflammatory, and antiapoptotic properties of sitagliptin to liver protection during IR injury has been well documented [13-18]. However, the drug effect on the liver profile of eicosanoids during IR has not been investigated, although sitagliptin has been demonstrated to reduce both PLA2 and COX2 concentration in various clinical and experimental settings [34,35]. Consistently, sitagliptin pretreatment of IR animals prevented significant elevation of 6-ketoPGF $1 \alpha\left(\mathrm{PGI}_{2}\right), \mathrm{PGE}_{2}$, and 13,14-dihydro-PGE $1\left(\mathrm{PGE}_{1}\right)$ and reduced 6-ketoPGF $1 \alpha$ $\left(\mathrm{PGI}_{2}\right) / \mathrm{TXB}_{2}\left(\mathrm{TXA}_{2}\right)$ ratio, elevated in IR. Interestingly, sitagliptin in control sham-operated animals had an opposite effect; it elevated the expression of 6-ketoPGF $1 \alpha\left(\mathrm{PGI}_{2}\right)$ and 6ketoPGF ${ }_{1 \alpha}\left(\mathrm{PGI}_{2}\right) / \mathrm{TXB}_{2}\left(\mathrm{TXA}_{2}\right)$ ratio, indicating that the biological effect of the drug is context-dependent.

Sitagliptin, but not IR, was responsible for an elevation of $\mathrm{PGD}_{2}$ and 15-deoxy-12,14$\mathrm{PGJ}_{2}\left(\mathrm{PGD}_{2}\right)$, significant solely in sitagliptin-pretreated control animals $\left(\mathrm{PGD}_{2}\right)$ or in both control and IR animals in ( $\mathrm{PGD}_{2}$ metabolite). The unfavorable proinflammatory character of $\mathrm{PGD}_{2}$ is manifested mostly in the lung and in allergic and autoimmune diseases, while in the liver, $\mathrm{PGD}_{2}$ has only recently been shown to alleviate the injury during IR [36]. Specifically, $\mathrm{PGD}_{2}$ metabolite 15 -deoxy- $\Delta 12,14$-prostaglandin $\mathrm{J}_{2}$ exerted hepatoprotective effects by alleviating oxidative stress via activation of Nrf2, reducing systemic inflammation and liver infiltration with macrophages, decreasing apoptotic rates, and by downregulating an expression of beclin-1 and LC3, autophagy markers. Activation of Nrf2 signaling in IR liver in response to sitagliptin without exploring the mechanism has previously been noted by Abdel-Gaber et al. [14]. Sitagliptin has also been shown to alleviate hepatic fibrosis by mechanisms involving the enhancement of Nrf2 expression accompanied by the downregulation of NFKB [37]. Therefore, our observation on sitagliptin-mediated upregulation of $\mathrm{PGD}_{2}$ and its metabolite in the context of its ability to induce Nrf2 signaling might shed some light on the molecular mechanism involved. $\mathrm{PGD}_{2}$ might also mediate, recently reported [38], sitagliptin-induced downregulation of LC3 and beclin-1 in endothelial cells. 
The number of studies on gliptins as attenuators of IR injury, which would explore possible mechanisms in addition to documenting drug anti-inflammatory and antioxidant properties, is limited. Sitagliptin, a competitive inhibitor of DPP4 also found to downregulate the enzyme expression [18], exerts its antidiabetic activity by preserving GLP-1, a peptide hormone synthesized by gut L cells [39]. GLP-1 and its analogs display antiapoptotic, anti-inflammatory, and antioxidant activities conferring protection during myocardial [40] and cerebral [41] IR. Consistently, sitagliptin attenuated intestinal IR injury by inducing GLP-1/GLP-1R signaling [26] and renal IR injury by upregulating GLP-1 secretion and local GLP-1R expression [23,42]. In the liver, GLP-1/GLP-1R has been speculated to mediate the upregulation of Nrf2 expression and subsequent elevation in heme oxygenase-1 [14]. Though, neither GLP-1R nor GLP-1 status in IR liver pretreated with sitagliptin has been investigated by the authors [14]. The speculation was based on, reported elsewhere [43], hepatoprotection conferred by activation of hepatic GLP-1R by receptor agonists. Cytoprotective effects of GLP-1 agonists have also been demonstrated in ischemic stroke [44] and myocardial infarct [45]. However, contrary to other organs, the presence of GLP-1R in the liver is controversial $[46,47]$. In the present study, GLP-1R mRNA expression was undetectable or borderline detectable in most of the examined livers, with six out of nine measurable cases $(\mathrm{Cq}<40)$ present in sitagliptin-treated animals. The GLP-1 concentration in the liver did not differ significantly between analyzed groups, although a non-significant peptide upregulation in IR animals could be noted. Still, IR was an independent predictor of GLP-1, regardless of sitagliptin pretreatment, exerting a positive effect on hormone concentration. The local concentration of IFN $\gamma$, in turn, was a negative predictor of hepatic GLP-1, corroborating previous observations on an inverse relationship between the hormone and IFN $\gamma$ signaling (reviewed in the work of [34]) and IFN $\gamma$ involvement in hepatic IR injury [48].

To elucidate potential mechanisms of sitagliptin action in hepatic IR injury, we examined the drug effect on other potential DPP4 substrates, namely VIP and SDF $\alpha$, and on their receptors. The VIP is a ubiquitous peptide hormone with anti-inflammatory and antioxidant properties, employing mainly VCAP1 and VCAP2 receptors. It can also interact with PACAP receptor (PAC1), although with lower affinity [49]. The VIP has been demonstrated to attenuate IR injury in mice liver [50] and rat lungs [51] and to protect rat kidneys from hemorrhagic ischemia and retransfusion [52]. Specifically, VIP has reduced liver infiltration with macrophages and neutrophils, increased concentration of anti-inflammatory IL-10, and decreased hepatocyte apoptotic rates while downregulating the expression of macrophage-derived TNF $\alpha$, IL-6, and IL-12 [50]. However, whereas Ji et al. [50] observed an elevation in hepatic VIP mRNA expression in response to IR, our results indicate the downregulation of peptide concentration, which was avoided by sitagliptin preconditioning. Our finding is consistent with accelerated peptide degradation owing to upregulated DPP4 expression in response to hypoxia (reviewed in the work of [53]). Moreover, it also agrees well with an observation made in lung IR injury on the DPP4 inhibition upregulating both VIP concentration and expression [51]. Supporting an inverse relation between VIP and IR injury, peptide concentration in the present study was inversely related to both inflammation and oxidative stress. PGE 2 and 3-BT concentrations were negative independent predictors of VIP concentration in addition to IR. In turn, VIP was an independent negative predictor of 6-ketoPGF1 $\alpha$, a stable metabolite of $\mathrm{PGI}_{2}$. The IR downregulated, and sitagliptin preconditioning also upregulated the expression of Vcap2, while Vcap1 expression was lower in all groups as compared to controls, significantly so in SIR. The IR was a sole, negative predictor of Vcap2 expression while that of Vcap1 was independently associated with oxidative stress marker Nox2 as a negative predictor and with Ptn, Mdk, and Sdf1 as positive predictors. Pleiotrophin (Ptn) and midkine (Mdk) are closely related to heparin-binding growth factors found to support liver regeneration [54] and protect against metal-induced liver toxicity [55] but being oppositely regulated in hepatic IR [17]. Moreover, pleiotrophin has been shown to play a cytoprotective role in brain and heart IR [56,57]. Midkine role during IR injury seems to depend on the affected 
organ as the cytokine exerted antiapoptotic, thus protective activity in the heart [58] but contributed to organ damage in the renal and hindlimb models of ischemia by promoting macrophage and neutrophil infiltration $[59,60]$.

Instead of activation of GLP-1/GLP-1R, the upregulated Nrf2 expression in the liver subjected to IR injury observed by Abdel-Gaber et al. [14] might be attributed to increased stability of SDF- $1 \alpha$. In lung IR injury models, SDF- $1 \alpha$ activates Nrf2 by triggering MAPK and PI3K/Akt pathways, the latter being also involved in SDF1 $\alpha$-mediated interference with NFKB signaling (reviewed in the work of [61]). However, as demonstrated here, hepatic IR had no effect on Sdf1 expression, and it elevated SDF-1 $\alpha$ concentration only non-significantly. This observation opposes the notion of increased expression of SDF$1 \alpha$ upon acute and chronic liver injury, where the cytokine can contribute to both liver regeneration and fibrosis. Those contradictory roles of SDF- $1 \alpha$ are believed to be executed by signaling via different receptors: pro-regenerative CXCR7 or profibrotic CXCR4 (reviewed in the work of [62]). Nonetheless, a known stimulatory effect of hypoxia and reactive oxygen species on SDF1 $\alpha$ and CXCR4 [63] was, in the case of $S d f 1$, reflected by Nampt and Nox4 being independent positive predictors of cytokine expression. In the case of CXCR4, receptor expression and concentration were significantly upregulated in IR animals, and the IR was an independent predictor of both Cxcr4 and CXCR4. Receptor overexpression has been detrimental in animal models of renal [64] and cardiac IR [65], in which it induces senescence in progenitor epithelial cells [64] or recruited inflammatory cells and increased production of inflammatory cytokines while inducing apoptosis in cardiomyocytes [65]. Antioxidants [66] and CXCR4 inhibitors [67] have been shown to prevent stress-induced receptor upregulation. In the liver, plerixafor, a specific receptor inhibitor, improves recovery of the liver following IR injury by restoring the proliferative potential of hepatocytes, hampered by CXCR4 signaling [67]. Inhibiting CXCR4 has proven effective also in attenuating oxidative stress-induced podocyte injury and renal fibrosis associated with activation of the SDF-1 $\alpha /$ CXCR4 axis [68]. In the present study, the IR animals that underwent sitagliptin preconditioning had significantly lower expression of $S d f 1$ and Cxcr4 as well as lower receptor concentration than animals subjected to IR procedure without preconditioning. This observation is in line with an unfavorable role of SDF-1 $\alpha /$ CXCR4 signaling in the liver [67], kidney [64,68], heart [65], or PC12 cells [66]. However, it opposes the response of endothelial [69] and progenitor endothelial cells to sitagliptin [70], in which the drug induced healing by employing SDF-1 $\alpha /$ CXCR4 signaling to increase the proliferative, migratory, and angiogenic potential of cells. In fact, the role of the SDF- $1 \alpha / C X C R 4$ axis in inflammatory diseases is rather ambiguous, as indicated by both beneficial and detrimental consequences of pathway inhibition [71].

\section{Materials and Methods}

\subsection{Experimental Setting}

The current study uses biobanked livers (stored at $-80^{\circ} \mathrm{C}$ ), collected during the original experiment $[15,16]$, which was conducted as briefly described below. The experiment was carried out on healthy animals to eliminate the harmful impact of diabetes on IR injury.

\subsubsection{Animals}

Male Wistar rats, 2-3 months old, were housed under standard conditions (12:12 h day/night cycle, stable temperature of $19-21{ }^{\circ} \mathrm{C}$, humidity of $45-60 \%$, and continuous ventilation) with free access to standard food and water.

\subsubsection{Chemicals}

Sitagliptin (Januvia-tablets $100 \mathrm{mg}$ ) was purchased from MSD (Warsaw, Poland), heparin (Heparinum WZF-ampoules 25,000 U/5 mL) from Polfa Warszawa (Warsaw, Poland), ketamine hydrochloride (Bio-ketan) from Vetoquinol Biowet (Gorzów Wlkp, Poland), medetomidine hydrochloride (Domitor, ampoules $1 \mathrm{mg} / \mathrm{mL}$ ) from Orion Pharma (Warsaw, Poland), butorphanol tartrate (Morphasol, ampoules $4 \mathrm{mg} / \mathrm{mL}$ ) from aniMedica 
GmbH (Frankfurt am Main, Germany), Ringer solution from Polfa Lublin S.A. (Lublin, Poland), and solution of $0.9 \%$ sodium chloride was obtained from Polpharma S.A. (Starogard Gdański, Poland).

\subsubsection{The IR Procedure}

After a handling period of 2-3 weeks, the rats were randomly divided into four groups. Two groups were sham-operated: the group without drug delivery (controls; $n=9$ ) and the group with sitagliptin ( $5 \mathrm{mg} / \mathrm{kg}$ p.o.) administered intragastrically two weeks prior to surgery once a day (sitagliptin, $n=8$ ). The remaining two groups were subjected to the IR procedure: one group without prior drug administration (IR, $n=9$ ) and one group where sitagliptin was administered in the same scheme as in the sitagliptin group (SIR, $n=10)$.

Before laparotomy, animals were anesthetized by the intramuscular administration of ketamine hydrochloride $(7 \mathrm{mg} / \mathrm{kg})$, medetomidine hydrochloride $(0.1 \mathrm{mg} / \mathrm{kg})$, and butorphanol tartrate $(2 \mathrm{mg} / \mathrm{kg})$. Ischemia of $70 \%$ of the liver (intermediate lobe and left lateral lobe) was induced as described previously $[15,16]$ by placing a microvascular clamp over the portal vein and hepatic artery. After $60 \mathrm{~min}$ of ischemia, the microclips were removed, allowing reperfusion for $24 \mathrm{~h}$. Animals in the non-ischemic groups underwent a sham surgery in which the blood vessels were isolated but not clamped. At the end of the experiment, the ischemic liver lobes were isolated and the fragments placed in a solution of RNAlater (Qiagen, Hilden, Germany) or frozen and stored at $-80{ }^{\circ} \mathrm{C}$ for metabolomic and immunoenzymatic analyses.

During reperfusion, the activity of aminotransferases, as markers of hepatocyte injury, was determined in rat sera by a certified laboratory using commercially available enzymatic methods and, after the surgical procedure, a histological evaluation was performed under a light microscope $[15,16]$.

\subsection{Analytical Methods}

4.2.1. Metabolomic Analysis of Eicosanoids

Chemicals and Reagents

Methanol, acetonitrile (ACN), ethyl acetate, water, formic acid (FA) were acquired from Merck Millipore (Warsaw, Poland). Standards of Thromboxane B2, Leukotriene B4, Prostaglandin D2, Prostaglandin E2, 6-keto Prostaglandin F1 $\alpha$, Prostaglandin F2 $\alpha, 15$ deoxy- $\Delta 12$,14-Prostaglandin J2, 13,14-dihydro Prostaglandin E1, and their isotope-labeled standards were procured from Cayman Chemical Company (Ann Arbor, MI, USA).

\section{Sample Preparation}

Tissue samples ( $\sim 0.5 \mathrm{~g})$ were homogenized using ceramic beads in $1 \mathrm{~mL}$ of LC-MSgrade water in Bead Ruptor Elite homogenizer (Omni International, Kennesaw, GA, USA). Aliquotes of $100 \mu \mathrm{L}$ of homogenates were mixed with $10 \mu \mathrm{L}$ of internal standard and $20 \mu \mathrm{L}$ of $0.2 \%$ FA in water. Samples were deproteinized and extracted with an ACN mixture with ethyl acetate. The obtained supernatants were evaporated to dryness and re-dissolved before analysis in $20 \% \mathrm{ACN}$ in water.

\section{LC-MS Analysis}

LC-MS data were obtained using Acquity UPLC system (Waters, Milford, MA, USA), equipped with a single quadrupole-time of flight mass analyzer and an electrospray (ESI) ion source (Xevo G2 Q-TOF MS from Waters). Spectra were obtained in negative ionization mode with the following MS parameters: the sprayer voltage and the desolvation temperature were set at $2.0 \mathrm{kV}$ and $450{ }^{\circ} \mathrm{C}$, respectively. All scans were carried out in an MS/MS QTOF scan mode. Data acquisition and calculations were performed with MassLynx and QuanLynx software (Waters), respectively. 
Analytes were separated using Acquity UPLC BEH Shield C18 $1.7 \mu \mathrm{m}$ chromatographic column $(100 \times 2.1 \mathrm{~mm}, 1.70 \mu \mathrm{m})$ from Waters with a linear gradient from $30 \%$ to $95 \%$ of mobile phase $B$ in 7.2 min with a total flow rate of $250 \mu \mathrm{L} / \mathrm{min}$. As mobile phases, $0.1 \% \mathrm{FA}$ in water $(\mathrm{A})$ and $0.1 \% \mathrm{FA}$ in $\mathrm{ACN}(\mathrm{B})$ were used.

\subsubsection{Immunoassays}

Rat livers ( $\sim 0.5 \mathrm{~g})$ were homogenized using ceramic lysing matrix beads in the Bead Ruptor Elite bead mill homogenizer (Omni International) with $0.5 \mathrm{~mL}$ of PBS buffer $\mathrm{pH} 7.4$ $\left(137 \mathrm{mM} \mathrm{NaCl}, 2.7 \mathrm{mM} \mathrm{KCl}, 10 \mathrm{mM} \mathrm{Na}_{2} \mathrm{HPO}_{4}\right.$, and $1.8 \mathrm{mM} \mathrm{KH}_{2} \mathrm{PO}_{4}$ ) with $1 \mathrm{mM}$ PMSF. Obtained homogenates were centrifuged $\left(12,000 \times g, 10 \mathrm{~min}, 4^{\circ} \mathrm{C}\right)$, and supernatants were collected, aliquoted, and stored at $-80^{\circ} \mathrm{C}$ until analysis.

Prior to analysis, tissue homogenates were clarified by centrifugation at $10,000 \times g$, $10 \mathrm{~min}, 4^{\circ} \mathrm{C}$.

The concentrations of GLP-1 (glucagon-like peptide-1) and VIP (vasoactive intestinal peptide) were determined using RayBio ${ }^{\circledR}$ Rat Enzyme Immunoassay Kits (\#EIAR-GLP1 and \#EIAR-VIP, respectively) from RayBiotech Life (Peachtree Corners, GA, USA) according to the manufacturer's instructions. Samples were diluted at 1:50 and tested in duplicates. Standard curves were drawn using 5-parameter logistic (PL) regression.

The C-X-C chemokine receptor type 4 (CXCR4) and C-X-C motif chemokine 12 $(C X C L 12 / S D F 1 \alpha)$ were determined using, respectively, Nori ${ }^{\circledR}$ Rat CXCR4 and Nori ${ }^{\circledR}$ Rat CXCL12 ELISA Kits (Genorise Scientific Inc., Glen Mills, PA, USA) following manufacturer's instructions. Samples were diluted 1:1 in Assay Buffer and tested in duplicates. The standard curves were calculated using a computer-generated 4-parameter logistic (PL) regression.

\subsubsection{Protein Determination}

Protein concentration was determined using Coomassie Plus (Bradford) Assay Kit (Thermo Scientific, Waltham, MA, USA) against the BSA standard curve according to the manufacturer's instructions. Samples were diluted in PBS and tested in duplicates.

Concentrations of eicosanoids and peptides/proteins were adjusted to protein content in the sample and expressed per $\mathrm{mg}$ of protein.

\subsubsection{Transcriptional Analysis}

A cDNA library has been prepared from isolated RNA as described in the original study $[15,16]$ and used for the present investigation.

All qPCR reactions were conducted in triplicates using the CFX96 platform (Biorad, Hercules, CA, USA) under standardized thermal cycling conditions: activation of the polymerase for $110 \mathrm{~s}$ at $95^{\circ} \mathrm{C}$ followed by 40 cycles of denaturation $\left(95^{\circ} \mathrm{C}\right.$ for $\left.5 \mathrm{~s}\right)$ and annealing and synthesis $\left(61.4^{\circ} \mathrm{C}\right.$ for $\left.5 \mathrm{~s}\right)$. Melting curve analysis $\left(60-95^{\circ} \mathrm{C}\right.$, reading every $0.5^{\circ} \mathrm{C}$ ) was conducted to confirm the specificity of the reaction product. The qPCR mixture consisted of $2 \mu \mathrm{L}$ of diluted 1:5 cDNA, $10 \mu \mathrm{L}$ of $2 \times$ SsoFast EvaGreen ${ }^{\circledR}$ Supermix (BioRad), $1 \mu \mathrm{L}$ of each $10 \mathrm{nM}$ forward and reverse target-specific primers, filled with water up to $20 \mu \mathrm{L}$. Primers were synthesized by Genomed (Warsaw, Poland) (Table 4). The relative gene expression was calculated as follows: geometric mean of all $\mathrm{Cq}$ values was subtracted from individual sample $\mathrm{Cq}(\Delta \mathrm{Cq})$, linearized by $2^{\Delta \mathrm{Cq}}$ conversion, and normalized to Gapdh expression. The resulting values are referred to as normalized relative quantities (NRQ) [72]. 
Table 4. Primers' sequences.

\begin{tabular}{ccc}
\hline Gene & Forward Sequence & Reverse Sequence \\
\hline Gapdh & TGACTCTACCCACGG-CAAGTTCAA & ACGACATACTCAGCACCAG-CATCA \\
S $x$ r 41 & GCTGGAGAGCGAGCATTG & TAGATGGTGGGCAGGAAGATCC \\
$P a c 1$ & CTCAACACTCCAAACTGTGCCC & GTCCAGGTACTCTTGGATCCAC \\
$V p a c 1$ & GGCTGTGCTGAGGCTCTATTTTG & AGGATGATGATGATGCCGATGA \\
$V p a c 2$ & GATGTGGGACAACCTCACCTG & TAACCATGAATGGGGGCAAAC \\
Glp1r & GGTGAGCAGCATCCACCCAG & TCACTAGTGCAGTTTTTGCTTA \\
\hline
\end{tabular}

4.2.5. Inflammatory Mediators and Markers of Oxidative, Nitrosative, and Halogenative Stress

Data on inflammatory mediators and markers of oxidative and halogenative stress were retrieved from our earlier published studies [16,17] for the purpose of correlation analysis.

\subsection{Statistical Analysis}

Data were analyzed using MedCalc ${ }^{\circledR}$ Statistical Software version 20.014 (MedCalc Software Ltd., Ostend, Belgium). Normality of data distribution and homogeneity of variances was established with Kolmogorov-Smirnov and Leven tests, respectively. Between-group comparisons were conducted using the Kruskal-Wallis H test with Conover post-hoc test, and results are presented as medians with interquartile range (IQR). Correlation analysis was conducted using Pearson correlation on log-transformed data, if appropriate. Multiple linear regression, a stepwise method, was applied to discern independent predictors of explained variables with explanatory variables entered into the model if $p<0.05$ and removed if $p>0.1$. The VIF (variance inflation factor) was calculated for each predictor variable to diagnose multilinearity. The repeated-measures ANOVA was conducted to discern IR and sitagliptin effect on the dynamics of liver enzymes activities. All calculated probabilities were two-tailed. The $p$ values $\leq 0.05$ were considered statistically significant.

\section{Conclusions}

In the present study, we demonstrated that hepatic IR is associated with an increase in tissue concentrations of 6-ketoPGF $1 \alpha\left(\mathrm{PGI}_{2}\right), \mathrm{PGE}_{2}$, and 13,14-dihydro-PGE 1 and with an elevated 6-ketoPGF $1 \alpha\left(\mathrm{PGI}_{2}\right) / \mathrm{TXB}_{2}\left(\mathrm{TXA}_{2}\right)$ ratio, which was abrogated by pretreatment of IR animals with sitagliptin. As the drug has an opposite effect regarding 6-ketoPGF $1 \alpha$ $\left(\mathrm{PGI}_{2}\right)$ and 6-ketoPGF $1 \alpha\left(\mathrm{PGI}_{2}\right) / \mathrm{TXB}_{2}\left(\mathrm{TXA}_{2}\right)$ ratio in control sham-operated animals, it might indicate that the biological effect of sitagliptin is context-dependent. We also showed that sitagliptin upregulated $\mathrm{PGD}_{2}$ and 15-deoxy-12,14-PGJ $\mathrm{J}_{2}$, which seems to be beneficial in the light of the recently reported hepatoprotective effect of the prostaglandin in the course of ischemia and reperfusion.

In order to shed some light on molecular mechanisms underlying favorable outcomes associated with sitagliptin pretreatment, we investigated drug effects on DPP4 substrates potentially relevant for liver protection during IR injury and on their receptors. We found that the IR upregulated Cxcr4/CXCR4 and downregulated VIP and Vpac2 but not in animals treated with sitagliptin.

Taken together, our results indicate that beneficial effects of sitagliptin during hepatic IR injury might be mediated by drug-induced normalization of proinflammatory prostanoids and upregulation of $\mathrm{PGD}_{2}$ and by concomitant downregulation of SDF$1 \alpha / C X C R 4$ and reinstating VIP/VCAP2 signaling.

Supplementary Materials: The following are available online at https:/ /www.mdpi.com/article/10 .3390/ijms222313155/s1.

Author Contributions: Conceptualization, M.K.-K., A.S. and M.T.; methodology, M.K.-K., M.G.F., P.F. and M.T.; formal analysis, M.K.-K., M.G.F. and M.T.; investigation, M.K.-K., M.G.F., P.F., K.G.-P., Ł.L., T.P. and B.K.; resources, M.K.-K., T.P., B.K., and M.T.; data curation, M.K.-K. and M.T.; writing- 
original draft preparation, M.K.-K., M.G.F. and M.T.; writing-review and editing, M.K.-K. and M.T.; visualization, M.K.-K.; supervision, M.K.-K., A.S. and M.T.; project administration, M.K.-K. and M.T.; funding acquisition, M.K.-K. and M.T. All authors have read and agreed to the published version of the manuscript.

Funding: The study was financed by Wroclaw Medical University statutory research funding SUB.A040.21.012, while the original experiment was financially supported by statutory research funding ST-555.

Institutional Review Board Statement: All procedures performed in the study were in accordance with the ethical standards of the institutional and/or national research committee. All applicable international, national, and/or institutional guidelines for the care and use of animals were followed. The experiment protocol was approved by the Local Ethics Committee on the Animal Research of the Institute of Immunology and Experimental Therapy Polish Academy of Sciences in Wroclaw (\#80/2012, 5 December 2012).

Informed Consent Statement: Not applicable.

Data Availability Statement: Data sharing is not applicable.

Conflicts of Interest: The authors declare no conflict of interest.

\section{References}

1. Rampes, S.; Ma, D. Hepatic ischemia-reperfusion injury in liver transplant setting: Mechanisms and protective strategies. J. Biomed. Res. 2019, 33, 221-234. [CrossRef]

2. Dar, W.A.; Sullivan, E.; Bynon, J.S.; Eltzschig, H.; Ju, C. Ischaemia reperfusion injury in liver transplantation: Cellular and molecular mechanisms. Liver Int. 2019, 39, 788-801. [CrossRef] [PubMed]

3. Smyth, E.M.; Grosser, T.; Wang, M.; Yu, Y.; FitzGerald, G.A. Prostanoids in health and disease. J Lipid Res. 2009, 50, S423-S428. [CrossRef]

4. Wang, B.; Wu, L.; Chen, J.; Dong, L.; Chen, C.; Wen, Z.; Hu, J.; Fleming, I.; Wang, D.W. Metabolism pathways of arachidonic acids: Mechanisms and potential therapeutic targets. Signal. Transduct. Target. Ther. 2021, 6, 94. [CrossRef]

5. Cheng, H.; Huang, H.; Guo, Z.; Chang, Y.; Li, Z. Role of prostaglandin E2 in tissue repair and regeneration. Theranostics 2021, 11, 8836-8854. [CrossRef]

6. Hamada, T.; Tsuchihashi, S.; Avanesyan, A.; Duarte, S.; Moore, C.; Busuttil, R.W.; Coito, A.J. Cyclooxygenase-2 deficiency enhances Th2 immune responses and impairs neutrophil recruitment in hepatic ischemia/reperfusion injury. J. Immunol. 2008, 180, 1843-1853. [CrossRef] [PubMed]

7. Abo-Youssef, A.M.; Messiha, B.A.S. The Protective Effect of Dexamethasone, Aspirin and Bromocriptine on Hepatic Ischemia/Reperfusion Injury in Rats. Res. J. Pharmacol. 2014, 8, 6-13.

8. Taghizadieh, M.; Hajipour, B.; Asl, N.A.; Khodadadi, A.; Somi, M.H.; Banei, M. Combination effect of melatonin and dexamethasone on liver ischemia/reperfusion injury. Bratisl. Lek. Listy 2016, 117, 47-53. [CrossRef] [PubMed]

9. Nishizawa, N.; Ito, Y.; Eshima, K.; Ohkubo, H.; Kojo, K.; Inoue, T.; Raouf, J.; Jakobsson, P.J.; Uematsu, S.; Akira, S.; et al. Inhibition of microsomal prostaglandin E synthase-1 facilitates liver repair after hepatic injury in mice. J. Hepatol. 2018, 69, 110-120. [CrossRef] [PubMed]

10. Wang, J.; Liu, Y.; Ding, H.; Shi, X.; Ren, H. Mesenchymal stem cell-secreted prostaglandin E2 ameliorates acute liver failure via attenuation of cell death and regulation of macrophage polarization. Stem Cell Res. Ther. 2021, 12, 15. [CrossRef] [PubMed]

11. Kuzumoto, Y.; Sho, M.; Ikeda, N.; Hamada, K.; Mizuno, T.; Akashi, S.; Tsurui, Y.; Kashizuka, H.; Nomi, T.; Kubo, A.; et al. Significance and therapeutic potential of prostaglandin E2 receptor in hepatic ischemia/reperfusion injury in mice. Hepatology 2005, 42, 608-617. [CrossRef] [PubMed]

12. Sherif, I.O.; Al-Shaalan, N.H. Vildagliptin attenuates hepatic ischemia/reperfusion Iinjury via the TLR4/NF- $\mathrm{B}$ B signaling pathway. Oxid. Med. Cell. Longev. 2018, 2018, 3509091. [CrossRef] [PubMed]

13. Song-Chol, M.; Hye-Sun, H. Dipeptidyl peptidase-4 inhibitor sitagliptin prevents hepatic injury via liver ischemia/reperfusion in rats. Int. J. Clin. Exp. Physiol. 2018, 5, 123-126. [CrossRef]

14. Abdel-Gaber, S.A.; Geddawy, A.; Moussa, R.A. The hepatoprotective effect of sitagliptin against hepatic ischemia reperfusioninduced injury in rats involves Nrf-2/HO-1 pathway. Pharmacol. Rep. 2019, 71, 1044-1049. [CrossRef]

15. Trocha, M.; Nowak, B.; Merwid-Ląd, A.; Szuba, A.; Dzięgiel, P.; Pieśniewska, M.; Gomułkiewicz, A.; Wiśniewski, J.; Piasecki, T.; Gziut, M.; et al. The impact of sitagliptin, inhibitor of dipeptidyl peptidase-4 (DPP-4), on the ADMA-DDAH-NO pathway in ischemic and reperfused rat livers. Adv. Clin. Exp. Med. 2018, 27, 1483-1490. [CrossRef] [PubMed]

16. Trocha, M.; Krzystek-Korpacka, M.; Merwid-Ląd, A.; Nowak, B.; Pieśniewska, M.; Dzięgiel, P.; Gomułkiewicz, A.; Kowalski, P.; Diakowska, D.; Szelag, A.; et al. Sitagliptin-dependent differences in the intensity of oxidative stress in rat livers subjected to ischemia and reperfusion. Oxid. Med. Cell. Longev. 2019, 2019, 2738605. [CrossRef] 
17. Trocha, M.; Fleszar, M.G.; Fortuna, P.; Lewandowski, Ł.; Gostomska-Pampuch, K.; Sozański, T.; Merwid-Ląd, A.; KrzystekKorpacka, M. Sitagliptin Modulates Oxidative, Nitrative and Halogenative Stress and Inflammatory Response in Rat Model of Hepatic Ischemia-Reperfusion. Antioxidants 2021, 10, 1168. [CrossRef] [PubMed]

18. Mun, S.C.; Hong, H.S. The effect of sitagliptin on hepatic ischemic reperfusion injury in rats. Med. J. Dr. DY Patil Vidyapeeth 2020, 13, 156-160. [CrossRef]

19. Bradic, J.; Milosavljevic, I.; Bolevich, S.; Litvitskiy, P.F.; Jeremic, N.; Bolevich, S.; Zivkovic, V.; Srejovic, I.; Jeremic, J.; Jovicic, N.; et al. Dipeptidyl peptidase 4 inhibitors attenuate cardiac ischaemia-reperfusion injury in rats with diabetes mellitus type 2 . Clin. Exp. Pharmacol. Physiol. 2021, 48, 575-584. [CrossRef]

20. Rankovic, M.; Jeremic, N.; Srejovic, I.; Radonjic, K.; Stojanovic, A.; Glisic, M.; Bolevich, S.; Bolevich, S.; Jakovljevic, V. Dipeptidyl peptidase-4 inhibitors as new tools for cardioprotection. Heart Fail. Rev. 2021, 26, 437-450. [CrossRef] [PubMed]

21. Glorie, L.L.; Verhulst, A.; Matheeussen, V.; Baerts, L.; Magielse, J.; Hermans, N.; D’Haese, P.C.; De Meester, I.; De Beuf, A. DPP4 inhibition improves functional outcome after renal ischemia-reperfusion injury. Am. J. Physiol. Renal Physiol. 2012, 303, F681-F688. [CrossRef]

22. Nuransoy, A.; Beytur, A.; Polat, A.; Samdanci, E.; Sagir, M.; Parlakpinar, H. Protective effect of sitagliptin against renal ischemia reperfusion injury in rats. Ren. Fail. 2015, 37, 687-693. [CrossRef]

23. Chang, M.W.; Chen, C.H.; Chen, Y.C.; Wu, Y.C.; Zhen, Y.Y.; Leu, S.; Tsai, T.H.; Ko, S.F.; Sung, P.H.; Yang, C.C.; et al. Sitagliptin protects rat kidneys from acute ischemia-reperfusion injury via upregulation of GLP-1 and GLP-1 receptors. Acta Pharmacol. Sin. 2015, 36, 119-130. [CrossRef]

24. El-Sahar, A.E.; Safar, M.M.; Zaki, H.F.; Attia, A.S.; Ain-Shoka, A.A. Sitagliptin attenuates transient cerebral ischemia/reperfusion injury in diabetic rats: Implication of the oxidative-inflammatory-apoptotic pathway. Life Sci. 2015, 126, 81-86. [CrossRef]

25. Abdel-Aziz, A.M.; Naguib Abdel Hafez, S.M. Sitagliptin protects male albino rats with testicular ischaemia/reperfusion damage: Modulation of VCAM-1 and VEGF-A. Andrologia 2020, 52, e13472. [CrossRef]

26. Khedr, R.M.; Ahmedt, A.A.E.; Kamel, R.; Raafat, E.M. Sitagliptin attenuates intestinal ischemia/reperfusion injury via cAMP/PKA, PI3K/Akt pathway in a glucagon-like peptide 1 receptor-dependent manner. Life Sci. 2018, 211, 31-39. [CrossRef] [PubMed]

27. Khedr, R.; Ahmed, A.; Kamel, R.; Rafaat, E. Antioxidant effects of sitagliptin in a rat model of intestinal ischemia/reperfusion injury. J. Adv. Pharm. Res. 2021, 5, 234-240. [CrossRef]

28. Hata, A.N.; Breyer, R.M. Pharmacology and signaling of prostaglandin receptors: Multiple roles in inflammation and immune modulation. Pharmacol. Ther. 2004, 103, 147-166. [CrossRef]

29. Hossain, M.A.; Wakabayashi, H.; Izuishi, K.; Okano, K.; Yachida, S.; Maeta, H. The role of prostaglandins in liver ischemiareperfusion injury. Curr. Pharm. Des. 2006, 12, 2935-2951. [CrossRef]

30. Nakamura, K.; Kageyama, S.; Ito, T.; Hirao, H.; Kadono, K.; Aziz, A.; Dery, K.J.; Everly, M.J.; Taura, K.; Uemoto, S.; et al. Antibiotic pretreatment alleviates liver transplant damage in mice and humans. J. Clin. Investig. 2019, 129, 3420-3434. [CrossRef]

31. Qiu, H.; Liu, J.Y.; Wei, D.; Li, N.; Yamoah, E.N.; Hammock, B.D.; Chiamvimonvat, N. Cardiac-generated prostanoids mediate cardiac myocyte apoptosis after myocardial ischaemia. Cardiovasc. Res. 2012, 95, 336-345. [CrossRef]

32. Yu, L.; Yang, B.; Wang, J.; Zhao, L.; Luo, W.; Jiang, Q.; Yang, J. Time course change of COX2-PGI2/TXA2 following global cerebral ischemia reperfusion injury in rat hippocampus. Behav. Brain Funct. 2014, 10, 42. [CrossRef]

33. Pushpakom, S.; Iorio, F.; Eyers, P.A.; Escott, K.J.; Hopper, S.; Wells, A.; Doig, A.; Guilliams, T.; Latimer, J.; McNamee, C.; et al. Drug repurposing: Progress, challenges and recommendations. Nat. Rev. Drug Discov. 2019, 18, 41-58. [CrossRef]

34. Lee, Y.S.; Jun, H.S. Anti-Inflammatory Effects of GLP-1-Based Therapies beyond Glucose Control. Mediat. Inflamm. 2016, 2016, 3094642. [CrossRef]

35. Lin, C.H.; Lin, C.C. Sitagliptin attenuates inflammatory responses in lipopolysaccharide-stimulated cardiomyocytes via nuclear factor-кB pathway inhibition. Exp. Ther. Med. 2016, 11, 2609-2615. [CrossRef]

36. Chen, K.; Li, J.J.; Li, S.N.; Feng, J.; Liu, T.; Wang, F.; Dai, W.Q.; Xia, Y.J.; Lu, J.; Zhou, Y.Q.; et al. 15-Deoxy- $\Delta 12,14-$ prostaglandin J2 alleviates hepatic ischemia-reperfusion injury in mice via inducing antioxidant response and inhibiting apoptosis and autophagy. Acta Pharmacol. Sin. 2017, 38, 672-687. [CrossRef]

37. Sharawy, M.H.; El-Kashef, D.H.; Shaaban, A.A.; El-Agamy, D.S. Anti-fibrotic activity of sitagliptin against concanavalin A-induced hepatic fibrosis. Role of Nrf2 activation/NF-kB inhibition. Int. Immunopharmacol. 2021, 100, 108088. [CrossRef]

38. Chang, X.M.; Xiao, F.; Pan, Q.; Wang, X.X.; Guo, L.X. Sitagliptin attenuates endothelial dysfunction independent of its blood glucose controlling effect. Korean J. Physiol. Pharmacol. 2021, 25, 425-437. [CrossRef]

39. Gilbert, M.P.; Pratley, R.E. GLP-1 Analogs and DPP-4 Inhibitors in Type 2 Diabetes Therapy: Review of Head-to-Head Clinical Trials. Front. Endocrinol. 2020, 11, 178. [CrossRef]

40. Matsubara, M.; Kanemoto, S.; Leshnower, B.G.; Albone, E.F.; Hinmon, R.; Plappert, T.; Gorman, J.H., 3rd; Gorman, R.C. Single dose GLP-1-Tf ameliorates myocardial ischemia/reperfusion injury. J. Surg Res. 2011, 165, 38-45. [CrossRef]

41. Abdel-latif, R.G.; Heeba, G.H.; Taye, A.; Khalifa, M.M.A. Lixisenatide, a novel GLP-1 analog, protects against cerebral ischemia/reperfusion injury in diabetic rats. Naunyn-Schmiedeberg's Arch. Pharmacol. 2018, 391, 705-717. [CrossRef] [PubMed]

42. Joo, K.W.; Kim, S.; Ahn, S.Y.; Chin, H.J.; Chae, D.W.; Lee, J.; Han, J.S.; Na, K.Y. Dipeptidyl peptidase IV inhibitor attenuates kidney injury in rat remnant kidney. BMC Nephrol. 2013, 14, 98. [CrossRef] 
43. Gupta, N.A.; Kolachala, V.L.; Jiang, R.; Abramowsky, C.; Romero, R.; Fifadara, N.; Anania, F.; Knechtle, S.; Kirk, A. The glucagonlike peptide-1 receptor agonist Exendin 4 has a protective role in ischemic injury of lean and steatotic liver by inhibiting cell death and stimulating lipolysis. Am. J. Pathol. 2012, 181, 1693-1701. [CrossRef]

44. Basalay, M.V.; Davidson, S.M.; Yellon, D.M. Neuroprotection in Rats Following Ischaemia-Reperfusion Injury by GLP-1 AnaloguesLiraglutide and Semaglutide. Cardiovasc. Drugs Ther. 2019, 33, 661-667. [CrossRef]

45. Sharma, A.; Verma, S. Mechanisms by Which Glucagon-Like-Peptide-1 Receptor Agonists and Sodium-Glucose Cotransporter-2 Inhibitors Reduce Cardiovascular Risk in Adults with Type 2 Diabetes Mellitus. Can. J. Diabetes 2020, 44, 93-102. [CrossRef]

46. Jin, T.; Weng, J. Hepatic functions of GLP-1 and its based drugs: Current disputes and perspectives. Am. J. Physiol. Endocrinol. Metab. 2016, 311, E620-E627. [CrossRef] [PubMed]

47. Müller, T.D.; Finan, B.; Bloom, S.R.; D’Alessio, D.; Drucker, D.J.; Flatt, P.R.; Fritsche, A.; Gribble, F.; Grill, H.J.; Habener, J.F.; et al. Glucagon-like peptide 1 (GLP-1). Mol. Metab. 2019, 30, 72-130. [CrossRef] [PubMed]

48. Klune, J.R.; Bartels, C.; Luo, J.; Yokota, S.; Du, Q.; Geller, D.A. IL-23 mediates murine liver transplantation ischemia-reperfusion injury via IFN- $\gamma /$ IRF-1 pathway. Am. J. Physiol. Gastrointest. Liver Physiol. 2018, 315, G991-G1002. [CrossRef] [PubMed]

49. Couvineau, A.; Laburthe, M. VPAC receptors: Structure, molecular pharmacology and interaction with accessory proteins. Br. J. Pharmacol. 2012, 166, 42-50. [CrossRef]

50. Ji, H.; Zhang, Y.; Liu, Y.; Shen, X.D.; Gao, F.; Nguyen, T.T.; Busuttil, R.W.; Waschek, J.A.; Kupiec-Weglinski, J.W. Vasoactive intestinal peptide attenuates liver ischemia/reperfusion injury in mice via the cyclic adenosine monophosphate-protein kinase a pathway. Liver Transpl. 2013, 19, 945-956. [CrossRef]

51. Jungraithmayr, W.; De Meester, I.; Matheeussen, V.; Inci, I.; Augustyns, K.; Scharpé, S.; Weder, W.; Korom, S. Inhibition of CD26/DPP IV attenuates ischemia/reperfusion injury in orthotopic mouse lung transplants: The pivotal role of vasoactive intestinal peptide. Peptides 2010, 31, 585-591. [CrossRef] [PubMed]

52. Erden, S.H.; Tunçel, N.; Aydyn, Y.; Sahintürk, V.; Koşar, M.; Tunçel, M. The effect of vasoactive intestinal peptide (VIP) and inhibition of nitric oxide on renal tissue injury of rats exposed to hemorrhagic ischemia and retransfusion: A possible interaction mechanism among mast cells and tissue histamine. Ann. N. Y. Acad. Sci. 1998, 865, 570-581. [CrossRef] [PubMed]

53. Matheeussen, V.; Jungraithmayr, W.; De Meester, I. Dipeptidyl peptidase 4 as a therapeutic target in ischemia/reperfusion injury. Pharmacol. Ther. 2012, 136, 267-282. [CrossRef] [PubMed]

54. Ochiai, K.; Muramatsu, H.; Yamamoto, S.; Ando, H.; Muramatsu, T. The role of midkine and pleiotrophin in liver regeneration. Liver Int. 2004, 24, 484-491. [CrossRef]

55. Yazihan, N.; Kocak, M.K.; Akcil, E.; Erdem, O.; Sayal, A. Role of midkine in cadmium-induced liver, heart and kidney damage. Hum. Exp. Toxicol. 2011, 30, 391-397. [CrossRef]

56. Miao, J.; Ding, M.; Zhang, A.; Xiao, Z.; Qi, W.; Luo, N.; Di, W.; Tao, Y.; Fang, Y. Pleiotrophin promotes microglia proliferation and secretion of neurotrophic factors by activating extracellular signal-regulated kinase 1/2 pathway. Neurosci. Res. 2012, 74, 269-276. [CrossRef] [PubMed]

57. Christman, K.L.; Fang, Q.; Kim, A.J.; Sievers, R.E.; Fok, H.H.; Candia, A.F.; Colley, K.J.; Herradon, G.; Ezquerra, L.; Deuel, T.F.; et al. Pleiotrophin induces formation of functional neovasculature invivo. Biochem. Biophys. Res. Commun. 2005, 332, 1146-1152. [CrossRef] [PubMed]

58. Horiba, M.; Kadomatsu, K.; Yasui, K.; Lee, J.K.; Takenaka, H.; Sumida, A.; Kamiya, K.; Chen, S.; Sakuma, S.; Muramatsu, T.; et al. Midkine plays a protective role against cardiac ischemia/reperfusioninjury through a reduction of apoptotic reaction. Circulation 2006, 114, 1713-1720. [CrossRef]

59. Sato, W.; Kadomatsu, K.; Yuzawa, Y.; Muramatsu, H.; Hotta, N.; Matsuo, S.; Muramatsu, T. Midkine is involved in neutrophil infiltrationinto the tubulointerstitium in ischemic renal injury. J. Immunol. 2001, 167, 3463-3469. [CrossRef]

60. Weckbach, L.T.; Groesser, L.; Borgolte, J.; Pagel, J.I.; Pogoda, F.; Schymeinsky, J.; Muller-Hocker, J.; Shakibaei, M.; Muramatsu, T.; Deindl, E.; et al. Midkine acts as proangiogenic cytokine in hypoxia-induced angiogenesis. Am. J. Physiol. Heart Circ. Physiol. 2012, 303, H429-H438. [CrossRef] [PubMed]

61. Beckers, P.A.J.; Gielis, J.F.; Van Schil, P.E.; Adriaensen, D. Lung ischemia reperfusion injury: The therapeutic role of dipeptidyl peptidase 4 inhibition. Ann. Transl. Med. 2017, 5, 129. [CrossRef] [PubMed]

62. Liepelt, A.; Tacke, F. Stromal cell-derived factor-1 (SDF-1) as a target in liver diseases. Am. J. Physiol. Gastrointest. Liver Physiol. 2016, 311, G203-G209. [CrossRef] [PubMed]

63. Chetram, M.A.; Hinton, C.V. ROS-mediated regulation of CXCR4 in cancer. Front. Biol. 2013, 8, 273-278. [CrossRef] [PubMed]

64. Chang, H.M.; Peng, K.Y.; Chan, C.K.; Sun, C.Y.; Chen, Y.Y.; Chang, H.M.; Huang, C.L.; Liu, P.C.; Chen, P.Y.; Wang, K.C.; et al. FGF23 ameliorates ischemia-reperfusion induced acute kidney injury via modulation of endothelial progenitor cells: Targeting SDF-1/CXCR4 signaling. Cell Death Dis. 2021, 12, 409. [CrossRef] [PubMed]

65. Chen, J.; Chemaly, E.; Liang, L.; Kho, C.; Lee, A.; Park, J.; Altman, P.; Schecter, A.D.; Hajjar, R.J.; Tarzami, S.T. Effects of CXCR4 gene transfer on cardiac function after ischemia-reperfusion injury. Am. J. Pathol. 2010, 176, 1705-1715. [CrossRef]

66. Zhang, J.; Fan, W.; Wang, H.; Bao, L.; Li, G.; Li, T.; Song, S.; Li, H.; Hao, J.; Sun, J. Resveratrol Protects PC12 Cell against 6-OHDA Damage via CXCR4 Signaling Pathway. Evid. Based Complement. Alternat. Med. 2015, 2015, 730121. [CrossRef]

67. Wilson, G.C.; Freeman, C.M.; Kuethe, J.W.; Quillin, R.C., 3rd; Nojima, H.; Schuster, R.; Blanchard, J.; Edwards, M.J.; Caldwell, C.C.; Lentsch, A.B. CXC chemokine receptor-4 signaling limits hepatocyte proliferation after hepatic ischemia-reperfusion in mice. Am. J. Physiol. Gastrointest. Liver Physiol. 2015, 308, G702-G709. [CrossRef] [PubMed] 
68. Mo, H.; Wu, Q.; Miao, J.; Luo, C.; Hong, X.; Wang, Y.; Tang, L.; Hou, F.F.; Liu, Y.; Zhou, L. C-X-C Chemokine Receptor Type 4 Plays a Crucial Role in Mediating Oxidative Stress-Induced Podocyte Injury. Antioxid. Redox Signal. 2017, 27, 345-362. [CrossRef]

69. Remm, F.; Kränkel, N.; Lener, D.; Drucker, D.J.; Sopper, S.; Brenner, C. Sitagliptin Accelerates Endothelial Regeneration after Vascular Injury Independent from GLP1 Receptor Signaling. Stem Cells Int. 2018, 2018, 5284963. [CrossRef] [PubMed]

70. Yu, G.; Liu, P.; Shi, Y.; Li, S.; Liu, Y.; Zhu, W. Sitagliptin Stimulates Endothelial Progenitor Cells to Induce Endothelialization in Aneurysm Necks Through the SDF-1/CXCR4/NRF2 Signaling Pathway. Front. Endocrinol. 2019, 10, 823. [CrossRef] [PubMed]

71. Seemann, S.; Lupp, A. Administration of AMD3100 in endotoxemia is associated with pro-inflammatory, pro-oxidative, and pro-apoptotic effects in vivo. J. Biomed. Sci. 2016, 23, 68. [CrossRef] [PubMed]

72. Hellemans, J.; Vandesompele, J. qPCR data analysis-Unlocking the secret to successful results. In PCR Troubleshooting and Optimization: The Essential Guide, 1st ed.; Kennedy, S., Oswald, N., Eds.; Caister Academic Press: Poole, UK, 2011 ; pp. 1-13. 